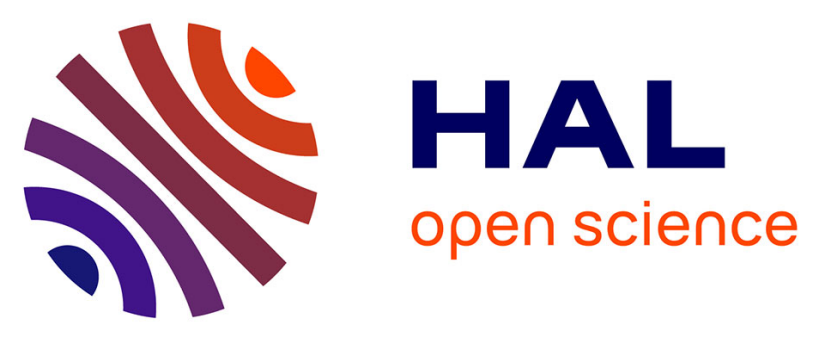

\title{
The XPB Subunit of the TFIIH Complex Plays a Critical Role in HIV-1 Transcription, and XPB Inhibition by Spironolactone Prevents HIV-1 Reactivation from Latency
}

Luisa Mori, Katharine Jenike, Yang-Hui Jimmy Yeh, Benoît Lacombe, Chuan Li, Adam J Getzler, Sonia Mediouni, Michael E Cameron, Matthew E Pipkin, Ya-Chi Ho, et al.

\section{- To cite this version:}

Luisa Mori, Katharine Jenike, Yang-Hui Jimmy Yeh, Benoît Lacombe, Chuan Li, et al.. The XPB Subunit of the TFIIH Complex Plays a Critical Role in HIV-1 Transcription, and XPB Inhibition by Spironolactone Prevents HIV-1 Reactivation from Latency. Journal of Virology, 2020, 95 (4), pp.e01247-20. 10.1128/jvi.01247-20 . hal-03321338

\section{HAL Id: hal-03321338 \\ https://hal.science/hal-03321338}

Submitted on 17 Aug 2021

HAL is a multi-disciplinary open access archive for the deposit and dissemination of scientific research documents, whether they are published or not. The documents may come from teaching and research institutions in France or abroad, or from public or private research centers.
L'archive ouverte pluridisciplinaire HAL, est destinée au dépôt et à la diffusion de documents scientifiques de niveau recherche, publiés ou non, émanant des établissements d'enseignement et de recherche français ou étrangers, des laboratoires publics ou privés. 
(1) JVI Accepted Manuscript Posted Online 25 November 2020

J Virol doi:10.1128/JVI.01247-20

Copyright $\odot 2020$ American Society for Microbiology. All Rights Reserved.

1 The XPB subunit of the TFIIH complex plays a critical role in HIV-1 transcription

2

3

4 Luisa Mori $^{a}$, Katharine Jenike ${ }^{b \bullet}$, Yang-Hui Jimmy Yeh $^{\mathrm{b}}$, Benoît Lacombe ${ }^{c}$, Chuan Li ${ }^{a}$,

5 Adam Getzler $^{a}$, Sonia Mediouni ${ }^{a}$, Michael Cameron ${ }^{\mathrm{a}}$, Matthew Pipkin ${ }^{\mathrm{a}}, \mathrm{Ya}-\mathrm{Chi} \mathrm{Ho}^{\mathrm{b}}$,

6 Bertha Cecilia Ramirez ${ }^{c^{*} \# \S}$, and Susana Valente ${ }^{\text {a\#§ }}$

7

8 a The Scripps Research Institute, Department of Immunology and Microbiology, Jupiter,

9 FL, USA 
HIV transcription requires assembly of cellular transcription factors at the HIV1promoter. The TFIIH general transcription factor facilitates transcription initiation by opening the DNA strands around the transcription start site and phosphorylating the Cterminal domain for RNA polymerase II (RNAPII) for activation. Spironolactone (SP), an FDA approved aldosterone antagonist, triggers the proteasomal degradation of the XPB subunit of TFIIH, and concurrently suppresses acute HIV infection in vitro. Here we investigated SP as a possible block-and-lock agent for a functional cure aimed at the transcriptional silencing of the viral reservoir. The long-term activity of SP was investigated in primary and cell line models of HIV-1 latency and reactivation. We show 
47 IMPORTANCE

48 Antiretroviral therapy (ART) effectively reduces an individual's HIV loads to below the detection limit, nevertheless rapid viral rebound immediately ensues upon treatment

50 interruption. Furthermore, virally suppressed individuals experience chronic immune 51 activation from ongoing low-level virus expression. Thus, the importance of identifying 52 novel therapeutics to explore in block-and-lock HIV functional cure approaches, aimed 53 at the transcriptional and epigenetic silencing of the viral reservoir to block reactivation 54 from latency. We investigated the potential of repurposing the FDA-approved 55 spironolactone (SP), as one such drug. SP treatment rapidly degrades a host 56 transcription factor subunit, XPB, inhibiting HIV transcription and blocking reactivation

57 from latency. Long-term SP treatment does not affect cellular viability, cell cycle 58 progression or global cellular transcription. SP alone blocks HIV transcription in the 59 absence of ART but does not delay rebound upon drug removal as XPB rapidly 60 reemerges. This study highlights XPB as a novel drug target in block-and-lock 61 therapeutic approaches. 


\section{INTRODUCTION}

Upon HIV-1 integration into the host genome the provirus becomes transcriptionally silent as the cell returns to a quiescent state (1). Despite effective antiretroviral therapy (ART) that suppresses HIV-1 replication to below the detection limit, these latent proviruses can reinitiate viral production upon cell stimulation or treatment interruption (2-4). The total elimination of this latent reservoir has become a major goal of HIV-1 eradication strategies and interventions involving latency modifying agents, immune therapies, or gene and cell-based therapies are being investigated (5-7). More recently though, HIV-1 remission or a functional cure have been explored $(8,9)$. A functional cure entails either null or sufficiently low viral replication that is controlled by the immune system in the absence of ART, while proviral DNA remains detectable. This would allow the prospect of functionally cured individuals maintaining undetectable viral loads in the absence of ART, without risk of onward transmission and no ongoing immunological damage that is associated with HIV infection (10-12). One such functional cure approach has been branded the block-and-lock approach, which aims at the transcriptional silencing of the viral reservoir (5). There are unfortunately no clinically available HIV-1 specific transcriptional inhibitors.

Transcription at the HIV-1 promoter begins with the assembly of the pre-initiation complex (PIC). The 5' long terminal repeat (LTR), which serves as the viral promoter, contains binding sites for multiple transcription factors (TFs) which bind sequentially to form the PIC. These include NF-kB, Sp1, TATA-binding protein (TBP) (as part of the general transcription factor TFIID), TFIIA, TFIIB and TFIIF, which together direct RNA polymerase II (RNAPII) binding to form a stable promoter complex (13-15). The PIC is 
completed by the addition of the TFIIE heterodimer and TFIIH (15). TFIIH is a tenprotein complex consisting of a core (XPB, XPD, p62, p52, p44, p34 and p8) and cyclindependent kinase (CDK)-activating kinase (CAK) subcomplex (CDK7, Cyclin $\mathrm{H}$ and MAT1) (16). TFIIH plays a crucial role in the initiation of transcription, but also in nucleotide excision repair, where bulky adducts are removed from damaged DNA (17). In transcription, once the PIC has assembled, the XPB subunit functions as a DNA translocase, feeding the DNA into the RNAPII cleft, introducing negative supercoiling and initiating the formation of the transcription bubble $(16,18,19)$. The CDK7 subunit is responsible for the initial activating phosphorylation of serine 5 in the heptapeptide repeats on the RNAPII (CTD) tail (pSer5) (20-22). Activated RNAPII clears the promoter, but rapidly stalls after transcribing the first $\sim 59$ nucleotides downstream of the transcription start site (TSS), which comprises a secondary structure termed the transactivation response element (TAR) (23). RNAPII stalls for a few reasons, namely its association with negative elongation factors, NELF and DSIF, as well as the presence of Nucleosome-1 (Nuc-1) downstream from the TSS that occlude efficient elongation (24-26). The high affinity interaction of the viral protein Tat, which is produced from rare full-length transcripts, with the TAR RNA allows recruitment of the positive elongation factor, P-TEFb, consisting of CyclinT1 and CDK9 (24, 25, 27-33). CDK9 phosphorylation of NELF (leading to detachment from RNAPII), DSIF (converts to an elongation factor), as well as Ser2 on the RNAPII CTD allows transcription to proceed $(34,35)$. Tat plays a fundamental role in HIV transcription and is key for the rapid and robust increase in full-length viral transcripts from the HIV genome upon reactivation from latency $(28,36-39)$. The proof-of-concept for the block-and-lock 
approach was shown with the small molecule inhibitor of Tat, didehydro cortistatin A $(\mathrm{dCA})$ in $\mathrm{CD}^{+} \mathrm{T}$ cells isolated from infected individuals and in the humanized mouse model of HIV latency (40-42). dCA directly interacts with the basic domain of Tat, blocking the interaction of Tat with TAR and preventing transcriptional elongation (40). As such, the long-term treatment of cells with dCA restricts RNAPII recruitment to the promoter and over time epigenetic marks are deposited at the HIV-1 promoter, promoting silencing and blocking reactivation from latency $(41,43,44)$.

In search for novel molecules that regulate HIV transcription to increase our portfolio of block-and-lock approaches, we studied the action of spironolactone (SP). SP is a potassium-sparing diuretic, an aldosterone antagonist that blocks binding to the mineralocorticoid receptor (MR), and has been approved since 1959 for the treatment of a range of conditions, including hypertension and heart failure (45). An off-target effect of SP is the proteasomal degradation of the ATP-dependent helicase, XPB subunit of the transcription factor TFIIH complex (46-49). XPB degradation is dependent on the $26 \mathrm{~S}$ proteasome and ubiquitinating enzymes (46). SP triggers XPB Ser90 phosphorylation by the CDK7 subunit of TFIIH leading to SCF ${ }^{\mathrm{FBX} 18}$ E3 ligase-mediated ubiquitination and proteasomal degradation (50). Despite XPB's critical role in transcription initiation $(14,16)$, its degradation was reported not to affect global transcription $(51,52)$. However, subsequent studies showed transcriptional inhibition of

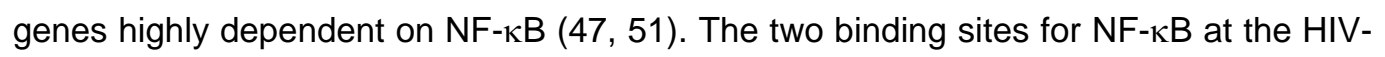
1 LTR allow NF-kB control of HIV-1 reemergence from latency (53). Lacombe et al. previously demonstrated that XPB degradation, by short-term treatment of cells with SP inhibits acute HIV-1 and HIV-2 transcription (48). 
Here, we explored the potential of SP as a block-and-lock agent, through long-

134

135

136

term treatment of latently infected cells and resting $\mathrm{CD} 4^{+} \mathrm{T}$ cells explanted from infected individuals. We demonstrated the ability of SP to inhibit HIV-1 transcription in latently infected cells and suppress reactivation from latency by potent LRAs, which correlated with loss of RNAPII recruitment to the HIV-1 promoter and genome, without damaging cellular effects. We confirmed the activity of SP was mediated by XPB via knockdown studies and is independent of the Tat-TAR interaction. Altogether, our results suggest that XPB plays a key role in HIV-1 transcriptional activation and its inhibition by SP blocks HIV-1 expression.

\section{RESULTS}

\section{Treatment of latently infected cell lines with SP inhibits transcription of HIV-1.} SP has been previously shown to block acute HIV infection of CD4+ $\mathrm{T}$ cells (48). Here to explore whether SP could be used in block-and-lock approaches to an HIV cure we investigated its ability to inhibit transcription from cell line models of latency. We studied SP activity in two established cell line models of latency, OM-10.1 and ACH-2 cells, in the presence of ART. OM-10.1 cells are a promyelocytic line derived from HL60 cells that survived an acute HIV-1 infection. Each cell contains a single integrated, full length provirus (54). SP treatment of these cells resulted in a dose-dependent reduction of HIV-1 capsid p24 in the supernatant, with an $\mathrm{IC}_{50}$ of $1.77 \mu \mathrm{M}$ (Fig. 1A). This inhibition correlated with a dose-dependent degradation of the cellular protein XPB (Fig. 1B). Eplerenone (EPL), a more selective mineralocorticoid receptor (MR) antagonist analog of SP, does not lead to XPB degradation $(46,47,51,55)$. As previously reported 
157 (48), no inhibition of HIV-1 was observed with increasing concentrations of EPL (Fig.

158 1C), suggesting the mechanism of HIV-1 inhibition is independent of MR antagonism.

159 No cytotoxicity was observed with up to $50 \mu \mathrm{M}$ SP or EPL following a $72 \mathrm{~h}$ incubation 160 (Fig. 1D).

Next, we evaluated the long-term effects of SP treatment. OM-10.1 cells were treated with $10 \mu \mathrm{M} \mathrm{SP}, 10 \mu \mathrm{M}$ EPL or DMSO for 190 days (Fig. 1E), and capsid p24 released into the supernatant was quantified by p24 ELISA. In OM-10.1 cells, SP rapidly inhibits viral production by approximately 2.5 logs, with capsid p24 levels stabilizing around the limit of detection $(3 \mathrm{pg} / \mathrm{ml})$. As expected, a reduction in the HIV-1 mRNA expression was observed in parallel (Fig. 1F, red line). The mRNA levels of the XPB gene, ERCC3, where either unaffected or slightly elevated by SP treatment (Fig. 1F, brown line). This confirms previous reports that degradation of XPB by SP is mediated by the $26 \mathrm{~S}$ proteasome and not by reduced XPB mRNA expression (46). Of note, the half-life of SP in long-term culture of OM-10.1 cells with ART was determined by LCMS/MS to be $2.3(+/-0.2)$ days and cells were split and treated every three days. All experiments were performed in the presence of ART unless otherwise stated. Of note, without ART the half-life is $2.9(+/-1.7)$ days). Altogether these results suggest that, in OM-10.1 cells, SP treatment combined with ART over time inhibits HIV-1 transcription to very low, frequently undetectable levels without obvious cytotoxic effects in the cells.

We next assessed the activity of SP in the $\mathrm{ACH}-2$ cell line, a T cell clone containing a single integrated provirus $(56,57)$, which harbors a C37T mutation TAR such that the Tat-TAR feedback loop is defective resulting in low transcription rates (58, 59). SP treatment of these cells resulted in a similar dose-dependent reduction of HIV-1 
capsid p24 in the supernatant, with an $\mathrm{IC}_{50}$ of $1.95 \mu \mathrm{M}$ (Fig. 2A), which correlated with a dose-dependent degradation of XPB (Fig. 2B). Again, EPL was inactive against HIV (Fig. 2C). Cytotoxicity was not observed up to $20 \mu \mathrm{M}$ of SP for a $72 \mathrm{~h}$ period, nor up to $50 \mu \mathrm{M}$ with EPL (Fig. 2D). The long-term treatment of $\mathrm{ACH}-2$ cells inhibited viral production by 1-1.5 logs, with capsid production stabilizing around 20-100 pg/ml (Fig. 2E). As expected, a reduction in cell associated HIV RNA was also observed (Fig. 2E), while levels of XPB mRNA were either unaffected or slightly elevated (Fig. 2F). No difference in cell viability or cell number was observed over time (Figure 2G). Differences in the magnitude of SP activity on HIV-1 p24 production between OM-10.1 and $\mathrm{ACH}-2$ cells may be related to the level of XPB degradation in these cell lines, $95 \%$ in $\mathrm{OM}-10.1$ cells as compared to $81 \%$ in $\mathrm{ACH}-2$ cells (Fig. 1B and $2 \mathrm{~B}$ ). Given that SP inhibits the transcription from proviruses with an incompetent Tat-TAR feedback loop, as is the case of $\mathrm{ACH}-2$ cells, the mechanism of action of SP is likely independent of the Tat-TAR interaction.

We also investigated the potential of SP to inhibit SIV $\mathrm{V}_{\text {mac239 }}$ in HUT-78 cells. Potent suppression of SIV replication with SP, but not EPL or DMSO was observed over a period of 12 days (Fig. 2G). This was accompanied by degradation of XPB by SP treatment as measured by Western blot on day 12 (Fig. 2H, inset panel). A rapid decline in cellular viability, due to cytotoxic effects of virus replication, was observed in DMSO and EPL treated cells where virus replication was allowed to proceed, whilst the viability of cells treated with $10 \mu \mathrm{M}$ SP was not adversely affected (Fig. 2l). These results suggest that SP may be used in latency studies in non-human primates infected with SIV. 
In sum, these results suggest that SP inhibits HIV-1 transcription in established cell line models of latency.

205

206

\section{RNA silencing of the XPB gene inhibits HIV-1 transcription.}

To confirm that HIV-1 inhibition by SP was truly dependent on XPB degradation, and not the result of an off-target effect, we knocked down the XPB gene, ERCC3, by shRNA and assessed viral replication. OM-10.1 cells were transduced with a lentiviral vector carrying either an ERCC3 specific shRNA or an shRNA targeting the GFP gene as control (since these cells do not contain GFP). In parallel, cells transduced with shGFP were treated with the $\mathrm{IC}_{50}=1.8 \mu \mathrm{M}$ and $\mathrm{IC}_{90}=6.3 \mu \mathrm{M}$ concentrations of $\mathrm{SP}$, as well as $10 \mu \mathrm{M} \mathrm{SP}$, to compare XPB levels and HIV replication. After $48 \mathrm{~h}$ of culture, cells were placed back on ART and selected with puromycin to enrich for cells containing the shRNA. After 10 days of puromycin selection, HIV-1 capsid production in the supernatant was measured by p24 ELISA, and cells were collected for RNA and Western blot analysis.

A knockdown efficiency of $70-80 \%$ at both the protein and RNA level (Fig. 3A-B) was achieved with the shRNA targeting ERCC3, while well tolerated by cells (Fig. 3C). Notably, SP treatment resulted in a slight upregulation of ERCC3 mRNA (Fig. 3B), as previously observed (Fig. 1F), which we suspect is a cellular compensatory mechanism

223 for the loss of XPB protein. When compared to cells transduced with the shGFP control, 224 the ERCC3 knockdown resulted in suppression of HIV gag mRNA and p24 production 225 to levels between the $\mathrm{IC}_{50}$ and $\mathrm{IC}_{90}$ concentrations of SP (Fig. 3D-E). 
Importantly, when we compared expression of additional TFIIH components, we observed substantial downregulation of XPD, CDK7 and cyclin $\mathrm{H}$ with $\mathrm{SP}$ treatment (Fig. 3F). With ERCC3 knock down, despite XPB downregulation similar to the $\mathrm{IC}_{50}$ and $\mathrm{IC}_{90}$ concentrations of SP, XPD was not downregulated (Fig. 3F). However, although not to the same degree as SP, a loss of CDK7 and Cyclin $\mathrm{H}$ were still detected (Fig. $3 F)$.

Altogether our results strongly support that the inhibition of HIV-1 transcription observed with SP treatment is the result of XPB degradation.

Treatment of latently infected cells with SP reduces HIV-1 reactivation from latency.

We next investigated whether SP treatment could block the reactivation of latent HIV-1 proviruses when cells were exposed to LRAs. The specific LRAs and doses chosen to reactivate each cell model were selected based on the ability to potently stimulate HIV-1 replication, with minimal toxicity. Prostratin, phorbol myristate acetate (PMA) and TNF- $\alpha$ activate transcription by induction of NF- $\mathrm{KB}$, while the histone deacetylase (HDAC) inhibitor suberoylanilide hydroxamic acid (SAHA) promotes chromatin acetylation, namely at nucleosome-1 on the HIV-1 LTR (60-63).

OM-10.1 and $\mathrm{ACH}-2$ cells were treated for 90 and 15 days, respectively, with 10 $\mu \mathrm{M}$ SP or DMSO and the levels of HIV-1 capsid production were monitored over time by p24 ELISA (Fig 4A-B). Cell number and viability remained stable over time (as in Figure 1 and 2). Once HIV levels had stabilized at maximal inhibition, the cells were treated with a panel of LRAs in the presence of ART and either $10 \mu \mathrm{M}$ SP or DMSO. After an 8 
$h$ incubation period cells were collected and viral transcription assessed by RT-qPCR to HIV nef mRNA. Robust reactivation was observed in DMSO+ART treated OM-10.1 and HIV-1 from latency when exposed to potent LRAs. 
SP treatment alone blocks viral reactivation; however, long-term SP treatment does not prevent viral rebound upon treatment interruption. The long term treatment of HIV-1 infected cells with the Tat inhibitor dCA results in the accumulation of epigenetic marks at the HIV-1 promoter, that render reactivation from latency very difficult to occur upon treatment interruption or stimulation with LRAs $(41,43,44)$. Thus, we investigated whether SP treatment over time would lead to similar effects. First, we tested whether $10 \mu \mathrm{M}$ SP alone was sufficient to maintain HIV transcription suppression in the absence of ART. As such, we washed off ART on day 69 from the OM-10.1 cell culture (three independent experiments) and measured viral p24 production in the supernatant (Fig. 5A, black arrows). A non-significant increase in HIV p24 production was observed in DMSO treated cells in the absence of ART (Fig. 8A, light blue line), while no such increase was observed in SP treated cells (Fig. 5A, orange line), suggesting SP treatment alone is able to block HIV replication in the absence of ART. Next, we assessed whether pre-treatment with SP would delay HIV rebound upon all treatment interruption, as such on day 78, DMSO and SP were washed off and cells maintained on ART alone (Fig. 5B, black arrow). As expected, HIV p24 levels remained stable in cells pre-treated with DMSO; however, within 12 days a rapid increase in virus replication back to DMSO levels was observed in cells pre-treated with SP (Fig. 8B orange line). Concomitantly, within 3 days of treatment interruption, we observed a rapid rebound in XPB protein levels, as well as other TFIIH components (XPD, CDK7 and Cyclin H) (Fig. 8C). In fact, XPB levels rebounded above the level of the DMSO control and remained elevated for at least 9 days post treatment interruption (Fig. $8 \mathrm{C}$, orange lanes vs light blue lanes). 
While pre-treatment with SP did not result in long-lasting epigenetic control of viral transcription upon treatment interruption, SP treatment alone seems sufficient to maintain HIV transcriptional inhibition in the absence of ART. These important results suggest that SP blocks HIV transcription as a single-therapy and holds great potential to be used in combination with other latency-promoting agents (LPAs), with the goal of establishing an epigenetic lock on the HIV genome.

\section{SP treatment reduces RNAPII recruitment to the HIV-1 genome.}

To confirm that transcriptional inhibition is the mechanism of action of SP against HIV, we investigated RNAPII recruitment to the HIV-1 genome. As such, we performed chromatin immunoprecipitation (ChIP) to RNAPII followed by RT-qPCR using primers recognizing the HIV-1 genome. We sought to identify differences in occupancy of total as well as phosphorylated Ser5 or Ser2 RNAPII (pSer5, pSer2 RNAPII).

Three independent long-term treatments ( 70 days) of OM-10.1 cells with DMSO+ART or SP+ART (see Fig. 4A) were treated or not with $1 \mu \mathrm{M}$ prostratin for $8 \mathrm{~h}$, resulting in mean 4.3-fold increase in p24 production and a mean 147-fold increase in HIV mRNA (data not shown) in DMSO+ART treated cells, with no detectable changes in p24 production in SP treated cells observed (but a mean 5.3-fold increase in HIV mRNA) (data not shown). These cells were crosslinked and prepared for RNAPII ChIP. Without prostratin, with or without SP, a small peak of RNAPII was observed at the HIV promoter, with very little occupancy throughout the genome (Fig. 6A). Modest reductions in occupancy of total, pSer5 and pSer2 RNAPII in unstimulated SP+ART treated cells were observed compared DMSO+ART control (Fig. 6B-C, red vs dark blue 
lines). Stimulation with prostratin led to a significant increase of total RNAPII occupancy in DMSO+ART treated cells, with a peak at the promoter and substantial occupancy throughout the genome (Fig. 6A, light blue line). As expected, a strong peak of pSer5 RNAPII was observed at the HIV promoter in DMSO+ART treated cells stimulated with prostratin, with a slight reduction in the gene body (Fig. 6B, light blue line). A peak of pSer2 RNAPII was observed at the HIV promoter of DMSO+ART treated cells stimulated with prostratin, drastically decreasing between nt positions 1000 and 3500, but increasing again towards the 3' end between positions 6000 and 9000 (Fig. 6C, light blue line). This is consistent with the role of pSer2 in relief of promoter-proximal pausing (mediated by P-TEFb $(65,66)$ ) and recruitment of splicing and RNA processing machinery (mediated by CDK13/12 (66-69)). A significant reduction of RNAPII occupancy (total, pSer5 and pSer2) was observed on the HIV genome when prostratin reactivation was performed in the presence of SP (Fig. 6A-C, orange lines). This is apparent at the HIV promoter, but most noticeable along the gene body. Almost no pSer5 RNAPII is observed along the HIV genome beyond the promoter in SP treated cells, while total and pSer2 RNAPII is still detected at the both the promoter and towards the 3'end of the genome. Importantly, no significant differences were observed in the occupancy of RNAPII (Total, pSer5, pSer2) on the promoter of GAPDH or in the gene body of RPL13A (Fig. 6D-F).

In sum, these results indicate that long-term treatment of cells with $10 \mu \mathrm{M} \mathrm{SP}$ significantly reduce RNAPII occupancy on the HIV genome, and potently suppresses RNAPII recruitment upon prostratin stimulation. These effects are not observed on the promoter or ORF of housekeeping genes. 


\section{Long-term effects of SP treatment on the cellular transcription apparatus and cell cycle progression.}

Previous reports have suggested that short term treatment of cells with $10 \mu \mathrm{M} S \mathrm{P}$ selectively degrades the XPB subunit of TFIIH, leaving other components mostly unaffected $(46,48)$. Additionally in short-term studies, using RNA-seq and uridine analog 5-ethynyluridine (EU) incorporation assays Alekseev et al did not observe global transcriptional defects in SP treated cells (51). We thus investigated the long-term effects of SP treatment on components of the TFIIH complex, as well as on a few important CDKs and respective cyclins. No significant differences were observed in the mRNA expression of any of the TFIIH components in OM-10.1 cells treated with SP for over 100 days (Fig. 7A, cells from 1D). However, at the protein level, although XPB was by far the most downregulated protein (over 95\%), a clear downregulation of other components of TFIIH (namely XPD, p62, CDK7 and Cyclin H) was observed at all time points, as compared to DMSO and EPL (Fig. 7B). In addition, in $\mathrm{ACH}-2$ cells treated for 15 days with $10 \mu \mathrm{M}$ SP, a similar, but more modest reduction in XPD, Cyclin $\mathrm{H}$ and CDK7 subunits of TFIIH was also observed (Fig. 7C). This downregulation of TFIIH components was detected as early as $72 \mathrm{~h}$ after treatment of OM-10.1 cells with $10 \mu \mathrm{M}$ SP and did not appear to magnify over time (Fig. 7D).

We also investigated whether long-term SP treatment affected the expression and function of other critical CDKs and their Cyclin partners, such as P-TEFb (CDK9 and Cyclin T1) and cell cycle proteins CDK2, Cyclin E1 and Cyclin A. No significant differences were observed between SP, vehicle or EPL treated OM-10.1 cells (Fig. 7B). 
Recently, CDK7 was shown to be the primary kinase responsible for CDK9 Ser175 phosphorylation, thought to bias CDK9's binding from BRD4 to Tat (30). Additionally, it was proposed that CDK7 phosphorylates CDK9 at Thr186, which is required for CDK9 activity, though CDK9 also autophosphorylates at this residue $(30,70)$. Given SP reduction of CDK7 protein expression (Fig. 7B,D), we compared the levels of pThr186 and pSer175 CDK9 by Western blot in SP and vehicle treated OM-10.1 cells treated for

24 days (Fig. 7E). While potent depletion of XPB and approximately $60 \%$ reduction in CDK7 was observed, the levels of total, pThr186 and pSer175 CDK9 remained unchanged. Furthermore, by propidium iodide staining, no differences in cell cycle progression between treatment groups were observed (Fig. 7F).

In sum, although long-term treatment of cells with $10 \mu \mathrm{M}$ SP results in a reduction in protein levels of additional components of the TFIIH complex besides XPB, we did not observe differences in the expression of other important kinases, cyclins, housekeeping genes, phosphorylation of CDK9 nor in cell cycle progression.

\section{Treatment of latently infected cells with SP reduces HIV transcription without} global dysregulation of cellular mRNA expression.

Due to the critical nature of TFIIH for RNAPII-mediated transcription, and the significant loss of some of the components of TFIIH, in addition to XPB (Fig. 3F, 6C, 7), we investigated global cellular mRNA synthesis defects that may occur with SP treatment. As such, we treated OM-10.1 cells for 15 days with either SP+ART or DMSO+ART (once maximal HIV inhibition had been achieved in the SP treated cells), followed by RNA extraction and mRNA-seq analysis. For this study, we included cells 
stimulated or not with the PKC agonist, prostratin to assess effects on activation dependent genes. HIV encoding genes were among the most significantly downregulated genes in cells treated with SP compared to DMSO control, particularly upon stimulation with prostratin (Fig. 8A, left and right panels, red points). Some of the most significantly affected cellular genes are highlighted and labelled in blue [pAdj<1e10 and abs(log2FoldChange) $>1$ for SP vs DMSO comparisons (left and right panels, Supplemental Tables S1-S2), and padj<1e-30 with an abs(log2FoldChange) $>2.5$ for Stim vs No stim comparisons (middle two panels, Supplemental Tables S3-S4)]. In unstimulated cells, treatment with SP resulted in the upregulation of 49 genes and downregulation of 25 as compared to DMSO control (Fig. 8A left panel, pAdj $<=0.05$, $\log 2 \mathrm{FC}>=\operatorname{abs}(1))$. Prostratin stimulation led to the differential expression of 758 genes in DMSO treated cells and 823 genes in SP treated cells (546 of which were differentially expressed between conditions) (Fig. 8A, middle panels). SP treatment, while specifically affecting the expression of some genes, does not appear to affect all RNAPII-mediated transcription, in support of previous studies suggesting XPB depletion by SP does not affect global cellular transcription (51). To determine more rigorously what patterns of gene signaling pathways were affected by SP treatment, we performed gene set enrichment analysis (GSEA) (71). A bubble-lattice plot was constructed to highlight gene sets affected by SP treatment, where the color of the bubble represents the normalized enrichment score (NES) (indicating the number and differential intensity of the assessed genes in each indicated pathway) and statistical significance is indicated by the size of the bubble (Fig. 8B). HIV encoded genes were significantly down-regulated as compared to DMSO control, particularly under conditions of 
409 prostratin stimulation, indicating the strong specific effect of SP treatment on HIV

410 transcription (Fig. 8B). Of note, with this type of bubble representation of the data, it is

411 important to keep in mind the size of the gene set, for instance the MYC targets have

412 modest downregulation with SP treatment, but since there are 200 genes in this set the

413 NES score is high. On the other hand, downregulation of HIV genes is greater, but

414 because there are lot fewer genes in this set the NES is smaller. Genes related to DNA

415 packaging (histone and chromatin-related genes) were significantly upregulated in both

416 unstimulated and prostratin stimulated SP treated cells (Fig. 8B). Conversely, MYC

417 targets, E2F targets, and Type I IFN receptor binding genes were downregulated with

$418 \mathrm{SP}$ treatment, which increased in significance upon prostratin stimulation (Fig. 8B).

419 Furthermore, cellular (endogenous) genes involved in the late phases of the HIV life

420 cycle (reactome gene sets (72)) were modestly downregulated upon stimulation, which

421 include genes involved in transcription, RNA processing and export from the nucleus

422 (Fig. 8B). IFN- $\gamma$ response genes were slightly upregulated in unstimulated SP treated

423 cells, gaining significance upon stimulation (Fig. 8B). Other gene sets related to

424 transcription of the HIV genome, RNAPII transcription of snRNAs, RNAPII elongation,

425 IFN- $\alpha$ response, housekeeping and apoptosis were not substantially affected (Fig. 8B).

426 Heatmaps were constructed from transcripts per million (TPM) data to facilitate direct

427 comparison of gene expression with different lengths (Fig. 8C, Supplemental Table S5).

428 All HIV genes were clearly downregulated upon SP treatment and, although prostratin

429 stimulation increased HIV expression, this was substantially reduced compared to

430 DMSO treated cells (Fig. 8C, left panel). Because of the modest downregulation in

431 genes involved in the late phase of the HIV life cycle observed in the GSEA (Fig. 8B), 
432 we examined the expression of individual genes within this set. Expression of 433 transcription related genes such as TFIIH, P-TEFb, the SEC, NELF, DSIF and RNAPII 434 genes do not appear to be substantially affected by SP treatment (Fig. 8D, left panel). 435 Furthermore, no obvious differences in expression of RNA splicing, export, capping or 436 cleavage genes between SP and DMSO treated cells (Fig. 8C middle panel). These 437 results are consistent with previous results, in which SP did not affect the transcriptional 438 machinery and cell cycle progression (Fig. 7), but blocked HIV reactivation (Fig. 4). 439 Nonetheless, SP treatment does curiously seem to upregulate a large subset of DNA 440 packaging complex genes (Fig. 8C, right panel), which is often associated with defects 441 in cell cycle progression (73). However, this upregulation might not be biologically 442 significant since, as mentioned above, no obvious differences in cell division were 443 observed in SP treated cells (Fig. 7).

444 In sum, SP treatment results in robust suppression of HIV transcripts both in 445 unstimulated or prostratin stimulated cells, consistent with the observations in Figs.1-5. 446 While the expression of a few specific gene sets were significantly impacted by SP 447 treatment, we hypothesize that their fold change may not be biologically significant 448 since we observe no major defects were observed in cell growth and viability. 449 Nevertheless, the effects of SP treatment at concentrations sufficient to potently 450 degrade SP will need to be assessed in vivo.

451

\section{DISCUSSION}

453 Inhibiting transcription from latent proviruses is an increasingly attractive approach for a 454 functional cure for HIV-1. The long-term transcriptional inhibition of HIV-1 may lead to a 
sustained epigenetic repression with the potential to contain viral transcription even in the absence of $\operatorname{ART}(43,44)$. In addition, such transcriptional inhibition may reduce "blips", or moments of detectable viremia observed in some virally suppressed patients, as well as chronic immune activation that stems from the continuing trickling of HIV transcription and viral protein production observed under suppressive ART. To date, there are unfortunately no FDA approved HIV-1 transcriptional inhibitors available. In this study, we investigated the potential of the clinically approved drug SP, which targets HIV-1 in various cell line models and primary $\mathrm{CD}^{+} \mathrm{T}$ cells from virally suppressed individuals.

In agreement with previous studies, we observed a dose-dependent reduction of XPB protein levels with SP treatment (Fig. 1B and 2B) $(46-48,51)$, which parallels a dose-dependent reduction in HIV-1 replication (Fig. 1A and 2A). Here we showed that specific shRNA knockdown of XPB resulted in similar HIV inhibition, suggesting that HIV inhibition by SP treatment is specifically mediated by XPB protein levels (Fig. 3). Importantly, EPL, a more specific MR antagonist, does not inhibit HIV nor degrades XPB (Fig. 1C and 2C). Thus, HIV inhibition by SP is independent of MR antagonism and dependent on the degradation of the host helicase XPB. Contrary to previous reports that showed short term SP treatments selectively degrade XPB, leaving other subunits of TFIIH relatively intact $(47,48,51)$, we show that even after a short $72 \mathrm{~h}$ period the levels of XPD, p62, CDK7 and Cyclin $\mathrm{H}$, but not other cellular proteins, were significantly reduced (Fig. 3F, 5C and 7). These effects seem to be somewhat cell type specific, since they were more pronounced in $\mathrm{OM}-10.1$ as compared to $\mathrm{ACH}-2$ cells 
478 (Fig. 7B vs 7C). This could be explained either by more modest XPB degradation in $479 \mathrm{ACH}-2$ cells (Fig. 1B vs $2 \mathrm{~B}$ ) or it could be related to the absence of a functional Tat-TAR 480 feedback loop in $\mathrm{ACH}-2$ cells and this warrants further investigation. It remains to be 481 determined whether loss of other TFIIH subunits is due to destabilization of the complex 482 or to off-target proteasomal degradation. Of note, shRNA knockdown of the XPB gene, ERCC3, does not result in the same degree of TFIIH components loss (Fig. 3F). While reduction of XPB with ERCC3 shRNA knockdown was around that observed with 1.8 $\mu \mathrm{M}$ SP treatment, we do not observe any loss of XPD, and a more modest loss of CDK7 and Cyclin H. Importantly, ERCC3 knockdown showed no cytotoxic or cytostatic effects (Fig. 5 C). Although shRNA knockdown of XPB resulted in an $\sim 80 \%$ reduction of XPB protein (similar to treatment with $1.8 \mu \mathrm{M} \mathrm{SP}$, Fig. 3A), with less effects on other TFIIH components, it reduced HIV mRNA levels to a greater degree than $1.8 \mu \mathrm{M} \mathrm{SP}$ treatment, further suggesting that development of more specific XPB degraders may improve on SP potency and could potentially avoid unwanted off-target transcriptional activity as well as the other known effects of SP on the MR. explanted from HIV-infected virally suppressed individuals (Fig. 4E). While levels of HIV reactivation were substantially reduced with SP treatment (average of 27.6-fold), the levels of the housekeeping gene, POLR2A (encoding a subunit of RNAPII), were 500 modestly elevated (average of 2.5 -fold) (Fig.4F). The slight increase in POLR2A 
observed in primary cells upon SP treatment requires further investigation to determine whether this is a direct consequence of SP activity or is related to inhibition of HIV transcription. Of note, even if not statistically significant $(p=0.78)$, the mRNA-seq

analysis in OM-10.1 cells showed a slight increase in POLR2A expression in cells treated with SP stimulated with prostratin, as compared to DMSO (log2FC of 0.5$)$. Furthermore, there were no obvious changes in expression of other RNAPII subunits (Fig. 8D, middle panel). Importantly, SP treatment was shown to be sufficient to maintain HIV p24 production below the limit of detection in the absence of ART (Fig. 5A). These results highlight the potential of using SP as a single drug to maintain HIV-1 suppression once deep latency has been established, in the absence of ART. However, regardless of treatment duration in the latent models tested, transcription remains detectable and once SP treatment is interrupted there is rapid transcriptional rebound to control levels (Fig. 5B). This was not observed with treatment with dCA, where longer treatment periods led to undetectable levels of viral RNA and sustained viral inhibition when treatment was interrupted $(41,43)$. The reasons for this difference may be two-fold, on one hand since a host component of a transcription factor complex is involved, as soon as XPB is produced again above a certain threshold it can participate and jumpstart transcription from the viral promoter. In fact, the levels of XPB protein become elevated, and remain so for at least 9 days, upon removal of SP (Fig.5C), possibly due to elevated XPB mRNA levels with SP treatment (Fig. 1F). On the other hand, since transcriptional inhibition is not fully complete, the residual level of transcription may preclude epigenetic repressive mark deposition for complete silencing of the promoter 
524 locus. Future studies will address the benefits of combining SP treatment with other 525 transcriptional inhibitors, such as dCA.

526

527 The RNAPII CTD tail contains 52 repeats of the heptad $Y_{1} S_{2} P_{3} T_{4} S_{5} P_{6} S_{7}$ that serves as 528 a hotspot for post-translational modification to fine-tune transcription $(66,74-76)$. Hypophosphorylated RNAPII is recruited to the promoter and is primed for activation by phosphorylation of Ser7 by the CDK7 subunit of TFIIH. Additional phosphorylation of

531 Ser5 by CDK7 activates RNAPII to initiate transcription and escape the promoter, as such pSer5 levels are highest at the TSS but decrease toward the end of genes. Promoter-proximal pausing of RNAPII occurs due to repressive factors (DSIF and 534 NELF) and occlusion by Nuc-1. RNAPII pausing is relieved through CDK9 phosphorylation DSIF, NELF and Ser2 of RNAPII CTD, resulting in a pSer2 peak just downstream of the TSS. Further phosphorylation of Ser2 occurs as RNAPII moves along the gene body, mediated by CDK12/13, resulting in increasing pSer2 levels towards the 3' end of genes in the gene body and is associated with recruitment of RNA processing and splicing factors $(67,68,77,78)$. Spironolactone treatment results in a 541 particularly noticeable upon LRA stimulation (Fig. 6A-C). In unstimulated cells, little 542 RNAPII is recruited to the promoter of either SP or DMSO treated cells, given the low 543 basal HIV expression in these cells. Upon reactivation with prostratin, some RNAPII 544 was still detected at the TSS in SP treated cells, even with the robust loss of XPB. This 545 is not unexpected, since RNAPII is brought to the promoter during PIC formation, prior 546 to TFIIH recruitment $(14,15,17)$. However, since HIV transcription depends on the 
positive feedback loop driven by Tat, a reduction in elongation would result in a loss in recycling of RNAPII and reduced overall RNAPII occupancy at the promoter. RNAPII was barely observed in SP+ART treated cells downstream from the promoter, 550 compared to robust recruitment in DMSO+ART treated cells upon transcriptional 551 reactivation. This is consistent with the role of TFIIH in initiation and promoter clearance $552(16,18,19)$. Significantly, changes in RNAPII occupancy (total, pSer5 and pSer2 CTD) were not observed at either the promoter of GAPDH or the ORF of RPL13A (Fig. 6D-F),

suggesting that the HIV-1 genome is especially sensitive to perturbation of TFIIH and the reduction in RNAPII recruitment is specific to the HIV-1 genome. This is consistent with our own results (Fig. 8) and previous work which revealed genes highly dependent on NF- $\mathrm{kB}$ experience reduced RNAPII recruitment with SP treatment, while other more constitutively expressed genes were not affected (47). NF-кB has been shown to recruit TFIIH to the inactive RNAPII poised at the HIV TSS, to allow CDK7 phosphorylation of RNAPII CTD (53).

TFIIH is a critical general transcription factor, involved in the initiation of transcription most RNAPII-dependent genes, including $\operatorname{HIV}(14,15,19,53,79)$. However, XPB has been proposed to be dispensable for RNAPII-mediated transcription (51). Despite SP treatment mediating substantial XPB degradation and moderate loss of other TFIIH components, SP seems well tolerated by cells treated long-term. In addition, SP does not appear to interfere with cell cycle progression, it does not cause significant losses of P-TEFb or cell cycle proteins, and has no effect on phosphorylation of CDK9 (Fig. 1G, $2 \mathrm{G}, 3,7)$. In agreement, our mRNA-seq analysis suggests SP treatment specifically and 
570 potently inhibits HIV expression, while more modestly affecting a subset of cellular

571 genes (Fig. 8). We cannot exclude the possibility that HIV transcription is inhibited 572 indirectly through SP-mediated effects on cellular proteins, since GSEA revealed 573 modest reduction in genes involved in the late phase of the HIV life cycle (Fig. 8B). 574 However, SP did not cause obvious changes in the mRNA expression (TPM count data) of RNA processing genes (capping, cleavage, splicing or export) or RNAPII-related transcription factors (TFIIH, P-TEFb, super-elongation complex, NELF or DSIF) that

577 could have potentially explained the potent downregulation of HIV mRNA expression 578 (Fig. 8C). Intriguingly, histone and chromatin related genes (DNA packaging) were 579 among the most upregulated genes upon SP treatment (Fig. 8B-C). However, these 580 changes are probably not significant, since no changes in cell cycle progression were observed (Fig. 7).

Despite a $\sim 95 \%$ reduction in XPB levels, and between 20 and $60 \%$ reduction in some other components of TFIIH with $10 \mu \mathrm{M}$ SP treatment (Fig. 7), we hypothesize 584 there is sufficient amounts of this complex to support basal transcription. Activation dependent genes, such as cytokines and HIV, which require recruitment of large amounts of TFIIH may be more susceptible to XPB loss (47). These results are not 587 unexpected and are consistent with previous reports showing SP treatment does not globally reduce transcription, but rather more selectively inhibits HIV and NF-kBdependent transcription $(47,48,51)$. Interestingly, mRNA-seq differential expression 590 analysis revealed significant downregulation of $M Y C$ and MYC-target genes (Fig. 8B).

591 This is consistent with the known role of XPB regulating C-MYC expression through 592 FUSE binding protein (FBP) and the FBP Interacting Repressor (FIR) which bind to the 
593 Far Upstream Sequence Element (FUSE) $(80,81)$. FBP/FIR act in response to cellular 594 signals to control RNAPII pausing and release through interactions with the XPB subunit 595 of TFIIH to regulate MYC expression $(82,83)$. It is proposed that FUSE and FIR binding 596 to TFIIH regulates activation-dependent, but not basal MYC expression (82). The level 597 of TFIIH in cells is tightly regulated and correlates with transcriptional activity (84). Thus, 598 inhibits HIV transcription, directly via XPB degradation or indirectly via other altered 603 cellular genes, and the mechanisms behind the increased susceptibility of HIV to SP 604 treatment, compared to the majority of cellular genes (51).

605 we expect that inducible genes that become transcriptionally very active upon stimulation may be more susceptible to XPB degradation than those transcribed at a far lower rate.

Further studies are needed to determine the full extent by which SP treatment

Although SP has been very useful tool to tease out the role of XPB in transcription, it will take some additional monitoring for it to be explored for block-and-lock approaches in the clinic. The concentrations of SP needed for maximal XPB degradation and HIV-1 inhibition $(10 \mu \mathrm{M})$ is well above the peak serum concentrations reached in healthy volunteers administered $100 \mathrm{mg} \mathrm{SP}$ daily for 15 days of around $0.19 \mu \mathrm{M}$. The area under the curve $(A \cup C)$ at day 15, reflecting the actual body exposure to the drug was $0.55 \mu \mathrm{M}$, which would result in suboptimal XPB degradation (Fig.1B and 2B) (85). However, SP is used to treat women experiencing hair loss at $200 \mathrm{mg}$ daily without negative effects and transgender women take up to $400 \mathrm{mg}$ daily pre-surgery $(86,87)$. Additionally, the FDA has approved a four-week treatment of $400 \mathrm{mg}$ daily SP to 
616 diagnose hyperaldosteronism (88). The most common side effects reported at high 617 doses of SP are gynecomastia, and the more serious hyperkalemia, which requires 618 monitoring (89). XPB is also involved in nucleotide excision repair and has been 619 proposed as a means to sensitize cells to platinum-based cancer therapies (46). The 620 FDA noted that rats treated with $500 \mathrm{mg} / \mathrm{kg} /$ day (about 25 times the human 621 recommended daily dose of $200 \mathrm{mg}$ per day) had an increase in occurrence of benign 622 tumors. The risk of treating individuals with a dose of SP high enough to degrade XPB 623 would need to be assessed, and whether or not these side effects will be a major 624 drawback for clinical testing remains to be seen. SP has, however, great potential to be 625 used in combination with other therapies, given its very quick effects on HIV. One could 626 foresee the initial use of high doses of SP to reduce HIV-1 transcription to or below the 627 level of detection, at which point SP doses could be reduced and another inhibitor, such 628 as a Tat inhibitor, could be introduced to bring about a state of "deep latency", from 629 which rebound would be very difficult to occur. Future studies will investigate this 630 combination therapy. Furthermore, combination treatments may allow the use of 631 reduced dosages.

632 Altogether we showed here that targeting a host component of a transcription 633 factor complex, XPB, reduces HIV-1 transcription and reactivation from latency without 634 obvious adverse effects on cellular transcription. We show that SP acts additively with 635 ART to reduce HIV-1 transcription and block reactivation from latency upon stimulation 636 with LRAs. Even given some concerns with the high doses of SP required for XPB 637 degradation in vivo, our results warrant the exploration of SP as a therapeutic in "block638 and-block" approaches for a functional cure. 
MATERIALS AND METHODS

641 Cell lines and cell culture. OM-10.1 and $\mathrm{ACH}-2$ cells were obtained through the NIH 642 AIDS Reagent Program (from Dr. Butera, \# 1319 abd Dr. Folks, \# 349 respectively). 643 Cells were maintained in RPMI 1640 (Gibco) supplemented with $2.0 \mathrm{mM} \mathrm{L-}$ 644 glutamine/100 U/ml penicillin $/ 100 \mu \mathrm{g} / \mathrm{ml}$ streptomycin (Gibco) and 10\% heat-inactivated 645 FBS (Atlas Biologicals, catalog no. FS-0500-AD) (complete RPMI) and cultured at $37^{\circ} \mathrm{C}$ 646 and $5 \%$ CO2. Cells were passaged every three days and media was replaced with the 647 indicated concentrations of SP, EPL or DMSO and an ART cocktail (200 nM Lamivudine 648 (AIDS Reagent), $200 \mathrm{nM}$ raltegravir (Selleckchem, MK-0518), $100 \mathrm{nM}$ efavirenz (AIDS 649 Reagent)). SP was purchased from Sigma-Aldrich (\# 1619006), dissolved in DMSO 650 (Fisher Scientific, \# BP231-100). EPL was purchased from Sigma-Aldrich (\# E6657651 10MG) and dissolved in DMSO. Cell concentration and viability was measured using the 652 TC20 automated cell counter (Bio-Rad, \# 1450102) and trypan blue staining.

Infection of Hut78 cells with SIVmac239. Hut78 cells were infected as previously 655 described (90). Briefly, cells were infected overnight with SIVmac239. Cells were then 656 washed with phosphate buffer saline, split into 3 flasks and treated with DMSO, EPL or 657 SP $(10 \mu \mathrm{M})$ for 12 days. SIV replication was assessed every 3 days post-infection, by 658 measuring the viral capsid in the supernatant with p27 ELISA (Advances Bioscience 659 Laboratories, \# 5436).

660 
Determination of SP half-life in cell culture. Stability of SP was evaluated in cell culture using an ABSciex 5500 mass spectrometer run in multiple reaction monitoring mode. Cells were treated with $10 \mu \mathrm{M} \mathrm{SP}$ (with or without ART) and the concentration of SP was evaluated before and after $72 \mathrm{~h}$ incubation, at multiple time points. Cells were resuspended and treated with 2-times v:v acetonitrile to lyse the cells, precipitate cellular protein, and inactivate the virus. Samples were filtered through a 0.2 micron filter plate prior to injection onto the LC-MS/MS. LC conditions used a Thermo Betasil C18 $5 \mu, 50 \times 2.1 \mathrm{~mm}$ column with a linear gradient of $\mathrm{A}$ : water $+0.1 \%$ formic acid and $\mathrm{B}$ : acetonitrile with $0.1 \%$ formic acid $(10 \% \mathrm{~B}$ from $0-.5 \mathrm{~min}, 90 \% \mathrm{~B}$ at $2-3 \mathrm{~min}, 10 \% \mathrm{~B}$ at $4-6$ min). Detection of SP used the mass transition of 417.3à341. Half-life was calculated

671 by plotting the natural log of the percent remaining compound verses time where $T 1 / 2=$ $672 \ln (2) /$ slope of the linear regression.

673

p24 ELISA. The amount of HIV p24 capsid protein produced in the supernatant of 675 cultured cells was quantified using the antigen capture assay kit from Advanced BioScience Laboratories, Inc. (\# 5447), and performed according to manufacturer's protocol.

MTT Cell Proliferation assay. The viability and proliferation of cells treated with 680 increasing concentrations of SP and EPL were measured using the MTT assay 681 according to the manufacter's protocol (ATCC, \# 30-1010K). Cells were cultured in 96682 well plates (in triplicate per drug concentration) for $72 \mathrm{~h}$ prior to addition of the MTT 683 reagent (3-(4,5-dimethylthiazol-2-yl)-2,5-diphenyltetrazolium bromide). 
Western blots for OM-10.1, ACH-2 and HUT-78 cells. Cells were collected, washed and lysed with a $20 \mathrm{mM}$ HEPES [pH 8.0], $100 \mathrm{mM} \mathrm{KCl,} 0.2 \mathrm{mM}$ EDTA, $5 \mathrm{mM} \beta$ mercaptoethanol, 0.1\% IGEPAL CA-630, 10\% glycerol, and supplemented with complete EDTA-free protease inhibitor cocktail (Roche, \# 4693132001) on ice for 10 min. For pSer175 and pThr186 CDK9 Western blots we added phosphatase inhibitor cocktail 3 (Sigma-Aldrich, \# P0044-1ML). Protein concentration was determined using 691 the Bio-Rad Protein Assay Dye (\# 50000006). Equal amounts of total protein extract 692 were loaded, alongside the Precision Plus Protein ${ }^{\mathrm{TM}}$ All Blue protein standards (Bio693 Rad, \# 1610373) onto a pre-cast 4 - 20\% gradient stain-free protein gel (Bio-Rad, \# 4568094). Proteins were then transferred to a nitrocellulose membrane using the BioRad Trans-Blot@ TurboTM system (\# 1704270). Membranes were blocked with 5\% milk and probed with the following antibodies: anti-XPB (Sigma-Aldrich, \# X0879, diluted 1:2000), anti-XPD (Cell Signaling Technology, \# 11963S, diluted 1:1000), anti-CDK7 698 (Santa Cruz, sc-7344, diluted 1:500), Cyclin H (Cell Signaling Technology, \# 2927S, diluted 1:1000), p62 (Santa Cruz, sc-25329, diluted 1:500), Cyclin A2 (Cell Signaling 700 Technology, \# 4656S, diluted 1:1000), Cyclin E1 (Cell Signaling Technology, \# 4129S, 701 diluted 1:500), CDK2 (Cell Signaling Technology, \# 25465S, diluted 1:1000), CDK9 702 (Cell Signaling Technology, \# 2316S, diluted 1:1000), pThr186-CDK9 (Cell Signaling 703 Technology, \# 2549S), pSer175-CDK9 (kind gift from Jonathan Karn), $\beta$-tubulin 704 (proteintech, \# 66240-1-IG, diluted 1:10,000) and GAPDH (Santa Cruz, sc-32233, 705 diluted 1:1000) in 3\% BSA (or 5\% milk for the $\beta$-tubulin antibody). Secondary antibodies 706 were anti-mouse (GE Healthcare, \# NA931-1ML) diluted 1:10,000 or anti-rabbit (Sigma- 
Aldrich, catalog no. A0545), diluted 1:15,000, both conjugated to horseradish peroxidase. Bands were visualized using the Amersham ECL Prime Western Blotting Detection Reagent (GE Healthcare, \# RPN2236) and imaged on the Bio-Rad ChemiDoc XRS+ System .

711

Quantitative PCR of cell-associated RNA. Total RNA was extracted from cells using

713 RNeasy kit (Qiagen, \# 74106). RNA was DNase treated using the TURBO DNA-free ${ }^{\mathrm{TM}}$ 714 kit (Invitrogen, \# AM1907). cDNA was synthesized using random hexamer primers and 715 SuperScript III First Strand Synthesis kit (Invitrogen, \# 18080051). qPCR was performed 716 using SensiFAST ${ }^{\mathrm{TM}}$ SYBR ${ }^{\circledR}$ No-ROX Kit (Bioline, \# BIO-98020). Samples were run in

717 duplicate or triplicate. The mRNA expression was normalized to RPL13A mRNA 718 expression and the relative abundance was calculated $(\Delta \Delta \mathrm{Ct})$.

\section{qPCR primers}

721 RPL13A primers were purchased from Bio-Rad, PrimePCR SYBR Green Assay:

722 RPL13A Human \#10025637. XPB-F: GGATGAGTCAGGCACCAAAGT, XPB-R:

723 CTGGAGAGAAGGCTTCCAAGAA, XPD-F: CGACTACATCTACCCCGAGCA, XPD-R:

724 CATGATCAGGGCCAACAGGGA, CCNH-F: TCACCCCAGGATAATAATGCTCA,

725 CCNH-R: CAGTATCTGTTCAAGTGCCTTCT, CDK7-F:

726 GGAGCCCCAATAGAGCTTATACA, CDK7-R: TCCACACCTACACCATACATCC,

727 GTF2H1-F GACCTTGTTGTGAGTCAAGTGA, GTF2H1-R:

728 CCTGCTTATGATTGGATGTGGAA, GTF2H2-F: CGTATGGGATTTCCTCAGCAC, 729 GTF2H2-R: AGCCTCCTAATGTAAGCCCTG, GTF2H3-F: 
730 GAATGGCAGACTTGGAGACTTC, GTF2H3-R: GCAAAGTTTCTGTATGTTGACCC,

731 GTF2H4-F: ACCCCATTTTCCGCCAGAAC, GTF2H4-R:

732 CGGCGTACTTGTCAAGGGAG, GTF2H5-F: AAGACATTGATGACACTCACGTC,

733 GTF2H5-R: GGGAAAAAGCATTTTGGTCCATT, MNAT1-F:

734 GGTTGCCCTCGGTGTAAGAC, MNAT1-R: AGTTGCTCTTTCTGAGTGGAGT,

735 AllHIVmRNA-F: TTGCTCAATGCCACAGCCAT, AllHIVmRNA-R:

736 TTTGACCACTTGCCACCCAT, HIV early gag-F: GCGACTGGTGAGTACGCCAA, HIV

737 early gag-R: CCCCTGGCCTTAACCGAATTT.

738

739 ChIP qPCR primers

740 123-F: CCCTGATTGGCAGAACTACACAC, 123-R:

741 TCTACCTTATCTGGCTCAACTGGT, 326-F: GACAGCCGCCTAGCATTTCAT, 326-R:

742 CCACGCCTCCCTGGAAAGT, 412-F: CGAGAGCTGCATCCGGAGTACT, 412-R:

743 GAGGCTTAAGCAGTGGGTTCC, 1097-F: GCAGTCCTCTATTGTGTGCATCAA, 1097-

744 R: CCTGTGTCAGCTGCTGCTTG, 1477-F: CCATCAATGAGGAAGCTGCAGAA, 1477-

745 R: GGTGGATTATGTGTCATCCATCCT, 3582-F: CAGAAATACAGAAGCAGGGGCAA,

746 3582-R: GTGTGGGCACCCTTCATTCTT, 6352-F: GAGCAGAAGACAGTGGCAATGA,

747 6352-R: CACAGGTACCCCATAATAGACTGTG, 8885-F:

748 CCTGCTGTAAGGGAAAGAATGAGAC, 8885-R: CACCTCTTCCTCCTCTTGTGCT,

749 GAPDH-F: CCTCACGTATTCCCCCAGGTTTA, GAPDH-R:

750 AGCCACACCATCCTAGTTGCCT.

751 
752 Cell cycle stage analysis. OM-10.1 cells were treated long-term (80 to 100 days) with $753 \mathrm{ART}$ and $10 \mu \mathrm{M} \mathrm{SP}, 10 \mu \mathrm{M}$ EPL or DMSO, being split and treated every $72 \mathrm{~h}$. After $72 \mathrm{~h}$ 754 of incubation, $1 \times 10^{6}$ cells were collected per condition (in triplicate) for cell cycle 755 analysis. All centrifugation steps were performed at $500 \times \mathrm{g}$ for $5 \mathrm{~min}$. Fixation: Cells 756 were washed in 1X DPBS (Gibco, \# 14190-250) and then fixed in 66\% ice cold ethanol, 757 on ice, for at least $2 \mathrm{~h}$ or stored at $4{ }^{\circ} \mathrm{C}$ until the next day. Staining: Fixed cells were 758 equilibrated to room temperature, resuspended and pelleted. Fixing solution was 759 aspirated and cells were washed with 1X DPBS. The pellet was resuspended in $0.5 \mathrm{ml}$ 760 of FxCycle PI/RNase staining solution (Invitrogen, \# F10797) and stained for 15-30 min 761 at RT, protected form light. Cells were acquired on a BD LSRIl flow cytometer using the $762561 \mathrm{~nm}$ laser with the $617 / 25$ band pass filter.

Transduction of OM-10.1 cells. The Mission shRNAs targeting ERCC3 and GFP in the 765 pLKO.1-puro plasmid were purchased from Sigma-Aldrich (SHCLNG: TRCN0000359264 and SHC204 respectively). First, lentiviral vectors were prepared by transient transfection of $293 \mathrm{~T}$ cells, with the shRNA vector and packaging plasmids pMD2.g and psPAX2 (gifts from Didier Trono, Addgene plasmid \# 12259 and \# 12260)

769 at a molar ratio of 2:1:1 respectively. Transfections were performed using TransIT-LT1 770 transfection reagent (Mirus Bio LLC, \# MIR 2305) as per manufacturer's instructions. 771 Lentiviral virus-like particles (VLPs) were collected and filtered through a $0.45 \mu \mathrm{m}$ filter, 772 to remove cellular debris, at 48 and $72 \mathrm{~h}$ post-transfection. Filtered VLPs were 773 combined, quantified and stored at $-80^{\circ} \mathrm{C}$ until use. Three days prior to transduction, 774 media was changed on $\mathrm{OM}-10.1$ cells to remove ART, to allow successful transduction 
with the VLPS. OM-10.1 cells were transduced with equal M.O.I.s of lentiviral vectors in T25 flasks as follows: pLKO.1-shGFP, pLKO.1-ERCC3, pLKO.1-shGFP + $1.8 \mu \mathrm{M}$ SP, and pLKO.1-shGFP + 6.3 $\mu \mathrm{M} \mathrm{SP}$, in the presence of the indicated concentrations of SP. VLPs were added to cells and a non-transduced control was included. Cells were washed after an overnight incubation and ART (+/- the indicated SP concentrations) was added back to the media. Two days later, cells were selected with $1.5 \mu \mathrm{g} / \mathrm{ml}$ puromycin (Gemini Bio-Products, \# 400-128P). Cells were maintained in puromycin days post-puromycin selection cells were harvested for XPB protein analysis by Western blot and RNA expression analysis of ERCC3 and HIV by RT-qPCR. Additionally, supernatant was collected from each transduction for quantification of HIV capsid protein by p24 ELISA. Cells were counted and viability was determined by trypan blue staining, using the TC20 automated cell counter.

Latent HIV-1 reactivation. OM-10.1 cells (after 45 days of treatment with ART and 10 $\mu \mathrm{M}$ SP or DMSO) and ACH-2 cells (after 15 days of treatment with ART and $10 \mu \mathrm{M} \mathrm{SP}$ or DMSO) were stimulated (or not) with $1 \mu \mathrm{M}$ prostratin (Lc Laboratories, \# P-44621MG), 10 ng/ml TNF- $\alpha$ (Biolegend, \# 570104), $1 \mu \mathrm{M}$ SAHA (Lc Laboratories, \# V8477_1g) or 20 nM PMA (Sigma-Aldrich, \# P1585-1MG). This was done in the presence of ART and either $10 \mu \mathrm{M}$ SP or DMSO. After $8 \mathrm{~h}$, p24 production was measured in the supernatant by ELISA and cells were collected for RNA extraction and RT-qPCR analysis. 
J-Lat A1 cells were treated with $160 \mathrm{nM}$ PMA or $1 \mathrm{ng} / \mathrm{ml}$ TNF- $\alpha$ for $2 \mathrm{~h}$ and then treated overnight with $10 \mu \mathrm{M} \mathrm{SP}$, EPL or DMSO, after which the mean fluorescence intensity of GFP was measured by flow cytometry. J-Lat 11.1 cells were treated with 8 $\mathrm{nM}$ PMA for $2 \mathrm{~h}$ following overnight treatment with $10 \mu \mathrm{M}$ SP, EPL or DMSO.

\section{Isolation, expansion and reactivation of primary CD4+ T cells}

804 infected individuals through magnetic negative depletion as previously described (91) and treated with SP $(10 \mu \mathrm{M})$ or mock (DMSO) for $24 \mathrm{hrs}$. The fusion inhibitor enfurvitide was supplemented to the cell culture to prevent new rounds of infection. In the final 6 hrs of culture, the cells were treated with PMA $(50 \mathrm{ng} / \mathrm{mL})$ and ionomycin $(1 \mu \mathrm{M})$ to induce maximum ex vivo latency reversal as previously described (64). Cell-associated HIV-1 RNA was extracted using TRIzol phase separation and DNase treatment. HIV-1 RNA expression was measured by RT-qPCR as cell-associated polyadenylated HIV-1 811 levels per million CD4+ T cells $(92,93)$. Cellular gene expression (POLR2A, Thermo 812 Fisher, \# 4331182) was measured as cell-associated polyadenylated POLR2A levels per million CD4+ T cells.

RNA polymerase II ChIP. Three independent treatments of OM-10.1 cells with ART and $10 \mu \mathrm{M}$ SP or DMSO for $\sim 70$ days were stimulated (or not) with $1 \mu \mathrm{M}$ prostratin for 8 h. Supernatant and cells were collected for p24 ELISA and RT-qPCR analysis 818 respectively and remaining cells were crosslinked with $1 \%$ formaldehyde for 10 minutes 819 and quenched by $0.125 \mathrm{M}$ glycine for $5 \mathrm{~min}$ at room temperature. Cells were lysed using 

an SDS lysis buffer and lysates were sonicated 16 times for $10 \mathrm{~s}$ bursts on ice to 821 generate sheared chromatin of 200 to 400 nucleotides, in the presence of complete EDTA-free protease inhibitor cocktail (Roche, \# 4693132001) and phosphatase inhibitor cocktail 3 (Sigma-Aldrich, \# P0044-1ML). The protein concentration of the precleared sonicated lysate was determined using the Bradford protein assay. A $4 \%$ fraction of each sonicated lysate was reserved for the input control. $4 \mu \mathrm{g}$ (per condition) of each of the following antibodies, total RNAP II (Millipore, \# 05-623), pSer5 RNAPII CTD (Active Motif, \# 61986), pSer2 RNAPII CTD (Active Motif, \# 61984) or isotype controls, mouse IgG (Invitrogen, \# 31903) or rat-IgG (Thermo Fisher Scientific, \# 029602) were conjugated to Protein G Dynabeads (Thermo Fisher Scientific, \# 10003D) for 20 min, 830 rotating at RT. A total of $500 \mu \mathrm{g}$ pre-cleared protein lysate was added to the conjugated beads for IP overnight with rotation at $4^{\circ} \mathrm{C}$. Dynabeads were washed, using magnetic separation. Samples were then treated (including input samples) with freshly prepared digestion buffer (10 mM Tris-HCl, $1 \mathrm{mM}$ EDTA, 0.5\% SDS, $10 \mu \mathrm{g} / \mathrm{ml}$ RNase A (Thermo Scientific, \# EN0531)) at $37^{\circ} \mathrm{C}$ for $30 \mathrm{~min}$. Cross-links were reversed for at least $4 \mathrm{~h}$ 835 shaking (1000 rpm) at $65^{\circ} \mathrm{C}$ with $200 \mathrm{nM} \mathrm{NaCl}$. DNA samples were then treated with proteinase K (Fisher Scientific, \# BP1700100) shaking (1000 rpm) at $60^{\circ} \mathrm{C}$ for $1 \mathrm{~h}$.

837 Dynabeads were removed and DNA was purified using the QIAquick PCR Purification 838 kit (QIAGEN, \# 28106). qPCR was performed in 384-well format using SensiFASTTM 839 SYBR ${ }^{\circledR}$ No-ROX Kit (Bioline, \# BIO-98020). The average CT value of the lgG only 840 background for each primer was subtracted from the CT value using the HIV-1 primer. 841 The data were then normalized to input values using the following formula:

$842 \%$ of input $=[2-\partial \mathrm{CT}(\mathrm{IP})-2-\partial \mathrm{CT}(\lg \mathrm{g})] \times 4$. 


\section{4 mRNA-seq library preparation}

845 Total RNA was extracted using the RNeasy kit (Qiagen, \# 74106). RNA was DNase 846 treated using the TURBO DNA-freeTM kit (Invitrogen, \# AM1907). Total RNA quantified 847 on the Qubit 2.0 fluorometer and run on the Agilent 2100 Bioanalyzer RNA pico chip 848 (Agilent Technologies, Santa Clara, CA) for quality assessment. mRNA was selectively 849 isolated from total RNA (500ng) using poly-T oligos attached to magnetic beads 850 according to the manufacturer's guidelines in the NEBNext poly(A) mRNA magnetic isolation module (Cat. \#: E7490, NEB, Ipswich, MA). The library preparation from the enriched mRNA was conducted according to NEBNext Ultra II Directional RNA kit (Cat. 853 \# E7760, NEB, Ipswich, MA). Briefly, the enriched mRNA samples were chemically 854 fragmented at $94^{\circ} \mathrm{C}$ for 15 minutes. The fragmented RNA was random hexamer primed and reverse transcribed to generate the first strand cDNA. The second strand was synthesized after removing the RNA template and incorporating dUTP in place of dTTP.

857 The incorporation of dUTP quenches the second strand during the PCR amplification step later and therefore the strand information was preserved. The purified ds cDNA was end repaired and adenylated at their 3 ' ends. A corresponding ' $T$ ' nucleotide on the 860 adaptors was utilized for ligating the adaptor sequences to the ds cDNA. The adaptor ligated DNA was purified and PCR amplified to incorporate unique barcodes to generate 862 the final libraries. The final libraries were validated on the bioanalyzer DNA chips, 863 pooled equally and loaded onto the NextSeq 500 for sequencing with $2 \times 80 \mathrm{bp}$ paired864 end chemistry. 


\section{Read mapping and differential expression analysis}

Raw FASTQC files were filtered for read quality using trim-galore version 0.6.1 with the options--clip_R1

$5 \quad$--clip_R2

$5 \quad--$ trim-n

-paired

(https://www.bioinformatics.babraham.ac.uk/projects/trim_galore/). Trimmed reads were

aligned to the human transcriptome (GRCh38v100) with the HIV genome added as an additional chromosome (REFSEQ release 202). To align transcripts, salmon version v0.14.1 was used with the -validateMappings option (94). Aligned transcriptomes were mapped to genes and differential gene expression was called using tximportv1.16.1 and DESeq2v1.28.1 respectively $(95,96)$. TPMs were determined using the countsFromAbundance $=$ "lengthScaledTPM" option in tximport. All plots were

876 generated in R. GSEAs were computed from the GSEA app v4.1.0 using TPMs as 877 counts and publicly available gene sets current as of October 2020 (71). DESeq2 and 878 TPM data can be found in Supplemental Tables S1-S5.

Statistical analysis. Statistics were performed using GraphPad Prism, and a P value of 881 $<0.05$ was considered significant for all comparisons. ${ }^{*} P<0.05$, ${ }^{* *} P<0.01$, ${ }^{\star \star *} P<$ 882 0.001. ${ }^{\star \star \star *} P<0.0001$. NS unless indicated. Data is presented as the mean of the indicated replicates with error bars indicating the SD. The two-tailed T-test was used where applicable, and a paired T-test was used for reactivation studies to compare stimulated to unstimulated conditions. Comparison of multiple conditions were performed using a two-way analysis ANOVA repeated-measures test (Dunnett or HolmSidak). 


\section{REFERENCES:}

1. Chun TW, Carruth L, Finzi D, Shen X, DiGiuseppe JA, Taylor H, Hermankova M, Chadwick K, Margolick J, Quinn TC, Kuo YH, Brookmeyer R, Zeiger MA, Barditch-Crovo P, Siliciano RF. 1997. Quantification of latent tissue reservoirs and total body viral load in HIV-1 infection. Nature 387:183-188.

2. Chun TW, Stuyver L, Mizell SB, Ehler LA, Mican JAM, Baseler M, Lloyd AL, Nowak MA, Fauci AS. 1997. Presence of an inducible HIV-1 latent reservoir during highly active antiretroviral therapy. Proc Natl Acad Sci U S A 94:1319313197.

3. Finzi D, Hermankova M, Pierson T, Carruth LM, Buck C, Chaisson RE, Quinn TC, Chadwick K, Margolick J, Brookmeyer R, Gallant J, Markowitz M, Ho DD, Richman DD, Siliciano RF. 1997. Identification of a reservoir for HIV-1 in patients on highly active antiretroviral therapy. Science (80- ) 278:1295-1300.

4. Wong JK, Hezareh M, Günthard HF, Havlir D V, Ignacio CC, Spina CA, Richman DD. 1997. Recovery of replication-competent HIV despite prolonged suppression of plasma viremia. Science (80- ) 278:1291-1295.

5. Darcis G, Van Driessche B, Van Lint C. 2017. HIV Latency: Should We Shock or Lock? Trends Immunol 38:217-228.

6. Marsden MD, Zack JA. 2019. HIV cure strategies: A complex approach for a complicated viral reservoir? Future Virol. Future Medicine Ltd London, UK.

7. Pitman MC, Lau JSY, McMahon JH, Lewin SR. 2018. Barriers and strategies to achieve a cure for HIV. lancet HIV 5:e317-e328.

8. Ruelas DS, Greene WC. 2013. An integrated overview of HIV-1 latency. Cell 155:519.

9. Sylla L, Evans D, Taylor J, Gilbertson A, Palm D, Auerbach JD, Dubé K. 2018. If We Build It, Will They Come? Perceptions of HIV Cure-Related Research by People Living with HIV in Four U.S. Cities: A Qualitative Focus Group Study. AIDS Res Hum Retroviruses 34:56-66.

10. Paiardini M, Müller-Trutwin M. 2013. HIV-associated chronic immune activation. Immunol Rev 254:78-101.

11. Sereti I, Altfeld M. 2016. Immune activation and HIV: An enduring relationship. Curr Opin HIV AIDS.

12. Klatt NR, Chomont N, Douek DC, Deeks SG. 2013. Immune Activation And HIV Persistence: Implications For Curative Approaches To Hiv Infection. Immunol Rev 254:326-342.

13. Olsen HS, Rosen CA. 1992. Contribution of the TATA motif to Tat-mediated transcriptional activation of human immunodeficiency virus gene expression. J Virol 66:5594-5597.

14. Compe E, Egly J-M. 2016. Nucleotide Excision Repair and Transcriptional Regulation: TFIIH and Beyond. Annu Rev Biochem 85:265-290.

15. Compe E, Genes CM, Braun C, Coin F, Egly JM. 2019. TFIIE orchestrates the recruitment of the TFIIH kinase module at promoter before release during transcription. Nat Commun 10.

16. Yan C, Dodd T, He Y, Tainer JA, Tsutakawa SE, Ivanov I. 2019. Transcription preinitiation complex structure and dynamics provide insight into genetic 
diseases. Nat Struct Mol Biol 26:397-406.

17. Compe E, Egly JM. 2012. TFIIH: When transcription met DNA repair. Nat Rev Mol Cell Biol 13:343-354.

18. Tomko EJ, Fishburn J, Hahn S, Galburt EA. 2017. TFIIH generates a six-basepair open complex during RNAP II transcription initiation and start-site scanning. Nat Struct Mol Biol 24:1139-1145.

19. Greber BJ, Toso DB, Fang J, Nogales E. 2019. The complete structure of the human TFIIH core complex. Elife 8.

20. Sandrock B, Egly JM. 2001. A Yeast Four-hybrid System Identifies Cdk-activating Kinase as a Regulator of the XPD Helicase, a Subunit of Transcription Factor IIH. $\mathrm{J}$ Biol Chem 276:35328-35333.

21. Coin F, Marinoni JC, Rodolfo C, Fribourg S, Pedrini AM, Egly JM. 1998. Mutations in the XPD helicase gene result in XP and TTD phenotypes, preventing interaction between XPD and the p44 subunit of TFIIH. Nat Genet 20:184-188.

22. Rossignol M, Kolb-Cheynel I, Egly JM. 1997. Substrate specificity of the cdkactivating kinase (CAK) is altered upon association with TFIIH. EMBO $\mathrm{J} 16: 1628$ 1637.

23. Kao SY, Calman AF, Luciw PA, Peterlin BM. 1987. Anti-termination of transcription within the long terminal repeat of HIV-1 by tat gene product. Nature 330:489-493.

24. Wada T, Takagi T, Yamaguchi Y, Watanabe D, Handa H. 1998. Evidence that PTEFb alleviates the negative effect of DSIF on RNA polymerase II-dependent transcription in vitro. EMBO J 17:7395-7403.

25. Yamaguchi Y, Takagi T, Wada T, Yano K, Furuya A, Sugimoto S, Hasegawa J, Handa H. 1999. NELF, a multisubunit complex containing RD, cooperates with DSIF to repress RNA polymerase II elongation. Cell 97:41-51.

26. Yamaguchi Y, Inukai N, Narita T, Wada T, Handa H. 2002. Evidence that Negative Elongation Factor Represses Transcription Elongation through Binding to a DRB Sensitivity-Inducing Factor/RNA Polymerase II Complex and RNA. Mol Cell Biol 22:2918-2927.

27. Garber ME, Jones KA. 1999. HIV-1 Tat: Coping with negative elongation factors. Curr Opin Immunol 11:460-465.

28. Peterlin BM, Price DH. 2006. Controlling the Elongation Phase of Transcription with P-TEFb. Mol Cell.

29. Garber ME, Mayall TP, Suess EM, Meisenhelder J, Thompson NE, Jones KA. 2000. CDK9 Autophosphorylation Regulates High-Affinity Binding of the Human Immunodeficiency Virus Type 1 Tat-P-TEFb Complex to TAR RNA. Mol Cell Biol 20:6958-6969.

30. Mbonye U, Wang B, Gokulrangan G, Shi W, Yang S, Karn J. 2018. Cyclindependent kinase 7 (CDK7)-mediated phosphorylation of the CDK9 activation loop promotes P-TEFb assembly with Tat and proviral HIV reactivation. J Biol Chem 293:10009-10025.

31. Zhu Y, Pe'ery T, Peng J, Ramanathan Y, Marshall N, Marshall T, Amendt B, Mathews MB, Price DH. 1997. Transcription elongation factor $P-T E F b$ is required for HIV-1 Tat transactivation in vitro. Genes Dev 11:2622-2632.

32. Wei P, Garber ME, Fang SM, Fischer WH, Jones KA. 1998. A novel CDK9- 
1010

1011

1012

1013

1014

1015

1016

1017

1018

1019

1020

1021

1022

1023

1024

1025

1026 associated C-type cyclin interacts directly with HIV-1 Tat and mediates its highaffinity, loop-specific binding to TAR RNA. Cell 92:451-462.

33. Bisgrove DA, Mahmoudi T, Henklein P, Verdin E. 2007. Conserved P-TEFbinteracting domain of BRD4 inhibits HIV transcription. Proc Natl Acad Sci U S A 104:13690-13695.

34. Fujinaga K, Irwin D, Huang Y, Taube R, Kurosu T, Peterlin BM. 2004. Dynamics of human immunodeficiency virus transcription: P-TEFb phosphorylates RD and dissociates negative effectors from the transactivation response element. Mol Cell Biol 24:787-95.

35. Ivanov D, Kwak YT, Guo J, Gaynor RB. 2000. Domains in the SPT5 Protein That Modulate Its Transcriptional Regulatory Properties. Mol Cell Biol 20:2970-2983.

36. Dingwall C, Ernberg I, Gait MJ, Green SM, Heaphy S, Karn J, Lowe AD, Singh M, Skinner MA. 1990. HIV-1 tat protein stimulates transcription by binding to a U-rich bulge in the stem of the TAR RNA structure. EMBO J 9:4145-53.

37. Dingwall C, Ernberg I, Gait MJ, Green SM, Heaphy S, Karn J, Lowe AD, Singh M, Skinner MA, Valerio R. 1989. Human immunodeficiency virus 1 tat protein binds trans-activation-responsive region (TAR) RNA in vitro. Proc Natl Acad Sci U S A 86:6925-6929.

38. Marshall NF, Price DH. 1995. Purification of P-TEFb, a transcription factor required for the transition into productive elongation. J Biol Chem 270:1233512338.

39. Razooky BS, Pai A, Aull K, Rouzine IM, Weinberger LS. 2015. A Hardwired HIV Latency Program. Cell 160:990-1001.

40. Mousseau G, Clementz MA, Bakeman WN, Nagarsheth N, Cameron M, Shi J, Baran P, Fromentin R, Chomont N, Valente ST. 2012. An Analog of the Natural Steroidal Alkaloid Cortistatin A Potently Suppresses Tat-Dependent HIV Transcription. Cell Host Microbe 12:97-108.

41. Mousseau G, Kessing CF, Fromentin R, Trautmann L, Chomont N, Valente ST. 2015. The tat inhibitor didehydro-cortistatin a prevents HIV-1 reactivation from latency. MBio 6:1-14.

42. Aoki S, Watanabe Y, Sanagawa M, Setiawan A, Kotoku N, Kobayashi M. 2006. Cortistatins A, B, C, and D, anti-angiogenic steroidal alkaloids, from the marine sponge Corticium simplex. J Am Chem Soc 128:3148-3149.

43. Kessing CF, Nixon CC, Li C, Tsai P, Takata H, Mousseau G, Ho PT, Honeycutt JB, Fallahi M, Trautmann L, Garcia JV, Valente ST. 2017. In Vivo Suppression of HIV Rebound by Didehydro-Cortistatin A, a "Block-and-Lock" Strategy for HIV-1 Treatment. Cell Rep 21:600-611.

44. Li C, Mousseau G, Valente ST. 2019. Tat inhibition by didehydro-Cortistatin A promotes heterochromatin formation at the HIV-1 long terminal repeat. Epigenetics Chromatin 12:23.

45. Delyani JA. 2000. Mineralocorticoid receptor antagonists: The evolution of utility and pharmacology, p. 1408-1411. In Kidney International.

46. Alekseev S, Ayadi M, Brino L, Egly JM, Larsen AK, Coin F. 2014. A small molecule screen identifies an inhibitor of DNA repair inducing the degradation of TFIIH and the Chemosensitization of tumor cells to platinum. Chem Biol 21:398407. 
47. Elinoff JM, Chen LY, Dougherty EJ, Awad KS, Wang S, Biancotto A, Siddiqui AH, Weir NA, Cai R, Sun J, Preston IR, Solomon MA, Danner RL. 2018.

Spironolactone-induced degradation of the TFIIH core complex XPB subunit suppresses NF-kB and AP-1 signalling. Cardiovasc Res 114:65-76.

48. Lacombe B, Morel M, Margottin-Goguet F, Ramirez BC. 2016. Specific Inhibition of HIV Infection by the Action of Spironolactone in T Cells. J Virol 90:1097210980.

49. Verma D, Thompson J, Swaminathan S. 2016. Spironolactone blocks EpsteinBarr virus production by inhibiting EBV SM protein function. Proc Natl Acad Sci 113:3609-3614.

50. Ueda M, Matsuura K, Kawai H, Wakasugi M, Matsunaga T. 2019. Spironolactone- induced XPB degradation depends on CDK7 kinase and SCF FBXL18 E3 ligase. Genes to Cells gtc.12674.

51. Alekseev S, Nagy Z, Sandoz J, Weiss A, Egly JM, Le May N, Coin F. 2017. Transcription without XPB Establishes a Unified Helicase-Independent Mechanism of Promoter Opening in Eukaryotic Gene Expression. Mol Cell 65:504-514.e4.

52. Titov D V., Gilman B, He QL, Bhat S, Low WK, Dang Y, Smeaton M, Demain AL, Miller PS, Kugel JF, Goodrich JA, Liu JO. 2011. XPB, a subunit of TFIIH, is a target of the natural product triptolide. Nat Chem Biol 7:182-188.

53. Kim YK, Bourgeois CF, Pearson R, Tyagi M, West MJ, Wong J, Wu SY, Chiang CM, Karn J. 2006. Recruitment of TFIIH to the HIV LTR is a rate-limiting step in the emergence of HIV from latency. EMBO J 25:3596-3604.

54. Butera ST, Perez VL, Wu BY, Nabel GJ, Folks TM. 1991. Oscillation of the human immunodeficiency virus surface receptor is regulated by the state of viral activation in a CD4+ cell model of chronic infection. J Virol 65:4645-4653.

55. Garthwaite SM, McMahon EG. 2004. The evolution of aldosterone antagonists, p. 27-31. In Molecular and Cellular Endocrinology.

56. Clouse KA, Powell D, Washington I, Poli G, Strebel K, Farrar W, Barstad P, Kovacs J, Fauci AS, Folks TM. 1989. Monokine regulation of human immunodeficiency virus-1 expression in a chronically infected human $\mathrm{T}$ cell clone. $\mathrm{J}$ Immunol 142:431-8.

57. Folks TM, Clouse KA, Justement J, Rabson A, Duh E, Kehrl JH, Fauci AS. 1989. Tumor necrosis factor $\alpha$ induces expression of human immunodeficiency virus in a chronically infected T-cell clone. Proc Natl Acad Sci U S A 86:2365-2368.

58. Cannon P, Kim SH, Ulich C, Kim S. 1994. Analysis of Tat function in human immunodeficiency virus type 1-infected low-level-expression cell lines $\mathrm{U} 1$ and ACH-2. J Virol 68:1993-7.

59. Emiliani S, Van Lint C, Fischle W, Paras P, Ott M, Brady J, Verdin E. 1996. A point mutation in the HIV-1 Tat responsive element is associated with postintegration latency. Proc Natl Acad Sci U S A 93:6377-6381.

60. Duh EJ, Maury WJ, Folks TM, Fauci AS, Rabson AB. 1989. Tumor necrosis factor a activates human immunodeficiency virus type 1 through induction of nuclear factor binding to the NF-KB sites in the long terminal repeat. Proc Natl Acad Sci U S A 86:5974-5978.

61. McKernan LN, Momjian D, Kulkosky J. 2012. Protein kinase C: One pathway 
towards the eradication of latent HIV-1 Reservoirs. Adv Virol 2012:1-8.

62. Archin NM, Espeseth A, Parker D, Cheema M, Hazuda D, Margolis DM. 2009. Expression of latent HIV induced by the potent HDAC inhibitor suberoylanilide hydroxamic acid. AIDS Res Hum Retroviruses 25:207-212.

63. Williams SA, Chen LF, Kwon H, Fenard D, Bisgrove D, Verdin E, Greene WC. 2004. Prostratin antagonizes HIV latency by activating NF-KB. J Biol Chem 279:42008-42017.

64. Bullen CK, Laird GM, Durand CM, Siliciano JD, Siliciano RF. 2014. New ex vivo approaches distinguish effective and ineffective single agents for reversing HIV-1 latency in vivo. Nat Med 20:425-429.

65. Kim JB, Sharp PA. 2001. Positive Transcription Elongation Factor b Phosphorylates hSPT5 and RNA Polymerase II Carboxyl-terminal Domain Independently of Cyclin-dependent Kinase-activating Kinase. J Biol Chem 276:12317-12323.

66. Bowman EA, Kelly WG. 2014. RNA Polymerase II transcription elongation and Pol II CTD Ser2 phosphorylation: A tail of two kinases. Nucl (United States) 5.

67. Davidson L, Muniz L, West S. 2014. 3' end formation of pre-mRNA and phosphorylation of Ser2 on the RNA polymerase II CTD are reciprocally coupled in human cells. Genes Dev 28:342-356.

68. Greifenberg AK, Hönig D, Pilarova K, Düster R, Bartholomeeusen K, Bösken CA, Anand K, Blazek D, Geyer M. 2016. Structural and Functional Analysis of the Cdk13/Cyclin K Complex. Cell Rep 14:320-331.

69. Liang K, Gao X, Gilmore JM, Florens L, Washburn MP, Smith E, Shilatifard A. 2015. Characterization of Human Cyclin-Dependent Kinase 12 (CDK12) and CDK13 Complexes in C-Terminal Domain Phosphorylation, Gene Transcription, and RNA Processing. Mol Cell Biol 35:928-938.

70. Baumli S, Lolli G, Lowe ED, Troiani S, Rusconi L, Bullock AN, Debreczeni JÉ, Knapp S, Johnson LN. 2008. The structure of P-TEFb (CDK9/cyclin T1), its complex with flavopiridol and regulation by phosphorylation. EMBO J 27:19071918.

71. Subramanian A, Tamayo P, Mootha VK, Mukherjee S, Ebert BL, Gillette MA, Paulovich A, Pomeroy SL, Golub TR, Lander ES, Mesirov JP. 2005. Gene set enrichment analysis: A knowledge-based approach for interpreting genome-wide expression profiles. Proc Natl Acad Sci U S A 102:15545-15550.

72. Fabregat A, Sidiropoulos K, Garapati P, Gillespie M, Hausmann K, Haw R, Jassal B, Jupe S, Korninger F, McKay S, Matthews L, May B, Milacic M, Rothfels K, Shamovsky V, Webber M, Weiser J, Williams M, Wu G, Stein L, Hermjakob H, D'Eustachio P. 2016. The reactome pathway knowledgebase. Nucleic Acids Res 44:D481-D487.

73. Günesdogan U, Jäckle H, Herzig A. 2014. Histone supply regulates S phase timing and cell cycle progression. Elife 3:e02443.

74. Egloff S, Murphy S. 2008. Cracking the RNA polymerase II CTD code. Trends Genet 24:280-288.

75. Komarnitsky P, Cho EJ, Buratowski S. 2000. Different phosphorylated forms of RNA polymerase II and associated mRNA processing factors during transcription. Genes Dev 14:2452-2460. 
76. Custódio N, Carmo-Fonseca M. 2016. Co-transcriptional splicing and the CTD code. Crit Rev Biochem Mol Biol.

77. Bartkowiak B, Liu P, Phatnani HP, Fuda NJ, Cooper JJ, Price DH, Adelman K, Lis JT, Greenleaf AL. 2010. CDK12 is a transcription elongation-associated CTD kinase, the metazoan ortholog of yeast Ctk1. Genes Dev 24:2303-2316.

78. Yoh SM, Cho H, Pickle L, Evans RM, Jones KA. 2007. The Spt6 SH2 domain binds Ser2-P RNAPII to direct Iws1-dependent mRNA splicing and export. Genes Dev 21:160-174.

79. Hoeijmakers JHJ, Egly JM, Vermeulen W. 1996. TFIIH: A key component in multiple DNA transactions. Curr Opin Genet Dev 6:26-33.

80. Er J, Lee A, Parsons LM, Quinn LM. MYC function and regulation in flies: how Drosophila has enlightened MYC cancer biology.

81. Zaytseva O, Quinn LM. 2017. Controlling the master: Chromatin dynamics at the MYC promoter integrate developmental signaling. Genes (Basel) 8:2-24.

82. Liu J, He L, Collins I, Ge H, Libutti D, Li J, Egly JM, Levens D. 2000. The FBP interacting repressor targets TFIIH to inhibit activated transcription. Mol Cell 5:331-341.

83. Liu J, Kouzine F, Nie Z, Chung HJ, Elisha-Feil Z, Weber A, Zhao K, Levens D. 2006. The FUSE/FBP/FIR/TFIIH system is a molecular machine programming a pulse of c-myc expression. EMBO J 25:2119-2130.

84. Donnio LM, Miquel C, Vermeulen W, Giglia-Mari G, Mari PO. 2019. Cell-type specific concentration regulation of the basal transcription factor TFIIH in XPBy/y mice model. Cancer Cell Int 19:237.

85. Gardiner P, Schrode K, Quinlan D, Martin BK, Boreham DR, Rogers MS, Stubbs K, Smith M, Karim A. 1989. Spironolactone metabolism: steady-state serum levels of the sulfur-containing metabolites. J Clin Pharmacol 29:342-7.

86. Sinclair R, Patel M, Dawson TL, Yazdabadi A, Yip L, Perez A, Rufaut NW. 2011. Hair loss in women: Medical and cosmetic approaches to increase scalp hair fullness. Br J Dermatol 165:12-18.

87. Prior JC, Vigna YM, Watson D. 1989. Spironolactone with physiological female steroids for presurgical therapy of male-to-female transsexualism. Arch Sex Behav 18:49-57.

88. Spark RF, Melby JC. 1968. Aldosteronism in hypertension. The spironolactone response test. Ann Intern Med 69:685-691.

89. Lachaine J, Beauchemin C, Ramos E. 2011. Use, tolerability and compliance of spironolactone in the treatment of heart failure. BMC Clin Pharmacol 11:4.

90. Mediouni S, Kessing CF, Jablonski JA, Thenin-Houssier S, Clementz M, Kovach MD, Mousseau G, De Vera IMS, Li C, Kojetin DJ, Evans DT, Valente ST. 2019. The Tat inhibitor didehydro-cortistatin A suppresses SIV replication and reactivation. FASEB J 33:8280-8293.

91. Ho YC, Shan L, Hosmane NN, Wang J, Laskey SB, Rosenbloom DIS, Lai J, Blankson JN, Siliciano JD, Siliciano RF. 2013. Replication-competent noninduced proviruses in the latent reservoir increase barrier to HIV-1 cure. Cell 155:540.

92. Shan L, Rabi SA, Laird GM, Eisele EE, Zhang H, Margolick JB, Siliciano RF. 2013. A Novel PCR Assay for Quantification of HIV-1 RNA. J Virol 87:6521-6525.

93. Pollack RA, Jones RB, Pertea M, Bruner KM, Martin AR, Thomas AS, Capoferri 
AA, Beg SA, Huang SH, Karandish S, Hao H, Halper-Stromberg E, Yong PC, Kovacs C, Benko E, Siliciano RF, Ho YC. 2017. Defective HIV-1 Proviruses Are Expressed and Can Be Recognized by Cytotoxic T Lymphocytes, which Shape the Proviral Landscape. Cell Host Microbe 21:494-506.e4.

94. Patro R, Duggal G, Love MI, Irizarry RA, Kingsford C. 2017. Salmon provides fast and bias-aware quantification of transcript expression. Nat Methods 14:417-419.

95. Soneson C, Love MI, Robinson MD. 2016. Differential analyses for RNA-seq: Transcript-level estimates improve gene-level inferences [version 2; referees: 2 approved]. F1000Research 4:1-23.

96. Love MI, Huber W, Anders S. 2014. Moderated estimation of fold change and dispersion for RNA-seq data with DESeq2. Genome Biol 15:1-21. 


\section{FIGURE LEGENDS}

Figure 1. SP treatment inhibits latent HIV-1 transcription in the OM-10.1 cell line model of latency.

(A) OM-10.1 cells were treated with ART and the indicated concentrations of SP for 72 $\mathrm{h}$, after which the amount of HIV capsid was measured in the supernatant by p24 ELISA. The $I_{50}$ value was calculated using GraphPad Prism. The line represents the mean of three independent experiments, each with three technical replicates. Error bars represent SD.

(B) Cells treated in (A) were collected for Western blot analysis with the indicated antibodies. Protein abundance was calculated by normalization to GAPDH levels and plotted relative to the DMSO control. A representative blot is shown above the quantification of three independent experiments. Error bars represent SD.

(C) OM-10.1 cells were treated with ART and the indicated concentrations of EPL for 72 $\mathrm{h}$ and the $\mathrm{IC}_{50}$ values calculated as in $(\mathrm{A})$.

(D) Cytotoxicity of SP (red) and EPL (blue) treated cells in OM-10.1 cells treated for 72 $h$ with increasing concentrations of SP was measured using an MTT assay and plotted as a percentage of the DMSO control. Error bars represent SD from three independent experiments.

(E) OM-10.1 cells were split and treated every $72 \mathrm{~h}$ in the presence of ART with $10 \mu \mathrm{M}$ SP (red), EPL (light blue) or vehicle only (DMSO, dark blue). HIV capsid production was quantified by p24 ELISA. The dotted black line at $3 \mathrm{pg} / \mathrm{ml}$ represents the limit of detection (I.o.d). This plot is representative of three independent experiments. 
1200

1201

1202

1203

1204

1205

1206

1207

1208

1209

1210

1211

1212

1213

1214

1215

1216 1217 represent SD.

1218

1219

1220

1221

(F) Cell associated HIV mRNA levels (red) and ERCC3 (XPB) mRNA levels (dark red) were measured at multiple time points during the long-term treatments of $\mathrm{OM}-10.1$ with $10 \mu \mathrm{M}$ SP in (D). cDNA was prepared from RNA extracted from cells pellets and qPCR performed with primers in the Nef region. The results were normalized as the number of viral mRNA copies per RPL13A mRNA and plotted relative to the DMSO treated control (blue, set to $100 \%$ for each time point). Error bars represent SD from the qPCR.

(G) The number of viable cells per $\mathrm{ml}$ of culture (left panel) and percentage viable cells (right panel), respectively, were measured by trypan blue staining and an automated cell counter every $72 \mathrm{~h}$ during the long-term treatments of OM-10.1 cells with $10 \mu \mathrm{M} \mathrm{SP}$, $10 \mu \mathrm{M}$ EPL or DMSO only.

Figure 2: Tat-TAR independent inhibition of the ACH-2 T cell model of HIV latency and suppression of SIV infection with SP treatment.

(A) ACH-2 cells were treated with ART and the indicated concentrations of SP for $72 \mathrm{~h}$, after which the amount of HIV capsid was measured in the supernatant by p24 ELISA. The IC50 value was calculated using GraphPad Prism. The line represents the mean of three independent experiments, each with three technical replicates. Error bars

(B) Cells treated in (A) were collected for Western blot analysis with the indicated antibodies. Protein abundance was calculated by normalization to GAPDH levels and plotted relative to the DMSO control. A representative blot is shown above the quantification of three independent experiments. Error bars represent SD. 
(C) $\mathrm{ACH}-2$ cells were treated with ART and the indicated concentrations of EPL for $72 \mathrm{~h}$ and the $\mathrm{IC}_{50}$ values calculated as in $(\mathrm{A})$.

(D) Cytotoxicity of SP (red) and EPL (blue) treated cells in ACH-2 cells treated for $72 \mathrm{~h}$ with increasing concentrations of SP was measured using an MTT assay and plotted as a percentage of the DMSO control. Error bars represent SD from three independent experiments.

(E) $\mathrm{ACH}-2$ cells were split and treated every $72 \mathrm{~h}$ in the presence of ART with $10 \mu \mathrm{M} \mathrm{SP}$ (red), EPL (light blue) or vehicle only (DMSO, dark blue). HIV capsid production was quantified by p24 ELISA. The dotted black line at $3 \mathrm{pg} / \mathrm{ml}$ represents the limit of detection (l.o.d). This plot is representative of three independent experiments.

(F) Cell associated HIV mRNA levels (red) and ERCC3 (XPB) mRNA levels (dark red) were measured at multiple time points during the long-term treatments of $\mathrm{ACH}-2$ cells with $10 \mu \mathrm{M}$ SP in (D). cDNA was prepared from RNA extracted from cells pellets and qPCR performed with primers in the Nef region. The results were normalized as the number of viral mRNA copies per RPL13A mRNA and plotted relative to the DMSO treated control (blue, set to $100 \%$ for each time point). Error bars represent SD from the qPCR.

(G) The number of viable cells per $\mathrm{ml}$ of culture (left panel) and percentage viable cells (right panel), respectively, were measured by trypan blue staining and an automated cell counter every $72 \mathrm{~h}$ during the long-term treatments of $\mathrm{ACH}-2$ cells with $10 \mu \mathrm{M} \mathrm{SP}$, $10 \mu \mathrm{M}$ EPL or DMSO only.

(H) HUT-78 cells were infected with SIV239 in the presence of $10 \mu \mathrm{M} \mathrm{SP}$ or $10 \mu \mathrm{M}$ EPL (or vehicle only, DMSO). Capsid production was monitored over time by p27 ELISA. 
Inset is a representative Western blot of XPB protein expression 12 days post infection,

1246 the housekeeping gene GAPDH is included as a loading control.

1247

(I) Viability of the HUT-78 cells in $(\mathrm{H})$ was measured by trypan blue staining using an automated cell counter. Error bars represent SD of two independent experiments.

1249

1250

1251

Figure 3. shRNA knockdown of the XPB gene, ERCC3, results in similar levels of HIV-1 inhibition in OM-10.1 cells.

1252

OM-10.1 cells were transduced with pLKO.1 puro lentiviral vector expressing either a control shRNA targeting GFP mRNA or an ERCC3 (XPB) shRNA. shGFP transduced 1254 cells were also treated with $1.8 \mu \mathrm{M}\left(\mathrm{IC}_{50}\right), 6.3 \mu \mathrm{M}\left(\mathrm{IC}_{90}\right)$ and $10 \mu \mathrm{M}$ SP. After 10 days of puromycin selection in the presence of ART and DMSO or indicated concentrations of 1256 SP cells were harvested for Western blot, p24 ELISA and RT-qPCR analysis.

(A) Quantification of the XPB Western blots from three independent experiments. XPB expression was normalized to $\beta$-tubulin expression and plotted as a percentage of the 1259 shGFP control.

1260 (B) ERCC3 (XPB) mRNA levels were measured by synthesizing cDNA from cell1261 associated RNA from transduced cells followed by RT-qPCR. Expression was 1262 normalized to RPL13A levels and plotted relative to the shGFP control.

1263 (C) The number of viable cells (left) and percentage of viable cells (right) were 1264 determined using trypan blue staining and an automated hemocytometer.

1265 (D) Cell associated HIV mRNA levels were quantified by RT-qPCR and normalized to 1266 RPL13A expression. Levels were plotted relative to the shGFP control. 
(E) The amount of HIV p24 capsid protein released into the supernatant of transduced OM-10.1 cells were measured by p24 ELISA.

1269

(F) Left panel: A representative Western blot of indicated proteins, from 3 independent experiments. The housekeeping genes GAPDH and $\beta$-Tubulin were included as loading controls. Right panel: Quantification of the XPD, CDK7 and Cyclin H Western blots, respectively, from three independent experiments. Protein expression was normalized to the respective housekeeping gene expression and plotted as a percentage relative to the shGFP control.

1275 Error bars represent the SD from three independent experiments. ${ }^{*} \mathrm{P}<0.05$, ${ }^{* *} \mathrm{P}<0.01$, ${ }^{* \star *} P<0.001 .{ }^{* * *} P<0.0001$. NS unless indicated. One-way ANOVA followed by the Dunnett multiple comparisons test.

Figure 4. SP treatment blocks HIV reactivation.

1282 three days the cells were split, treated and harvested for Western blot, p24 ELISA and 1283 RNA analysis. The amount of p24 capsid released into the supernatant of each culture 1284 was measured by p24 ELISA every three days.

(B) ACH-2 cells were treated for 15 days with ART and $10 \mu \mathrm{M} \mathrm{SP}$ or DMSO and treated 1286 as for OM-10.1 cells above (A).

1287 (C) After 45 days of treatment, OM-10.1 cells from (shown in A) were set aside from 1288 each long-term treatment with ART and $10 \mu \mathrm{M}$ SP (red) or DMSO (blue) and were 1289 stimulated with the indicated concentrations of LRAs for $8 \mathrm{~h}$. The amount of cell 
associated HIV mRNA was determined by RT-qPCR, normalized to RPL13A levels and 1291 plotted relative to the unstimulated DMSO control.

1292

(D) The same was done on day 15 of long-term ACH-2 treatments with ART and $10 \mu \mathrm{M}$ SP or DMSO (shown in B).

(E) Resting CD4+ T cells from 18 ART-treated, virally suppressed HIV-1 infected individuals were isolated from whole PBMCs. Patients had to have been on ART for $>1$ year with no blips in viral load in the past 6 months. Cells were treated with SP for $24 \mathrm{~h}$ in the presence of the fusion inhibitor, T20, to prevent new rounds of infection. In the final $6 \mathrm{~h}$ of treatment, cells were subjected to stimulation with PMA + lonomycin. The amount of HIV-1 RNA was measured per million cells.

(F) The amount of POLR2A mRNA was measured as in (E).

1301 The limit of detection (l.o.d.) is shown by the dotted line at $3.0 \mathrm{pg} / \mathrm{ml}$. Error bars 1302 represent the SD from three independent experiments. ${ }^{*} \mathrm{P}<0.05,{ }^{* \star} \mathrm{P}<0.01,{ }^{* \star *} \mathrm{P}<$ 0.001. ${ }^{* * * *} \mathrm{P}<0.0001$. NS unless indicated. A paired T-Test was used to compare 1304 stimulated to unstimulated for each respective treatment. A Wilcoxon matched-pairs 1305 signed rank test was used to calculate the $p$-values for $(E)$ and $(F)$.

1306

Figure 5. SP treatment of OM-10.1 cells suppresses HIV in the absence of ART, but pre-treatment does not delay rebound upon treatment interruption.

1309

(A) On day 69 of the long-term treatment of OM-10.1 cells with ART and $10 \mu \mathrm{M} \mathrm{SP}$ or

DMSO, some cells were set aside and washed to remove ART (indicated by the black

1311 arrows) and maintained alongside the treatments with ART. Cells were then treated 1312 every three days with either DMSO + ART (dark blue), $10 \mu \mathrm{M} \mathrm{SP}+\mathrm{ART}$ (red), DMSO 
with no ART (light blue) and $10 \mu \mathrm{M} \mathrm{SP}$ with no ART (orange). The amount of HIV capsid

1314 released into the supernatant was monitored over time by p24 ELISA.

1315

(B) On day 78 of the long-term treatment of OM-10.1 cells with ART and $10 \mu \mathrm{M} \mathrm{SP}$ or

DMSO, some cells were set aside and washed to remove treatments with DMSO or SP

1317 (indicated by the black arrow). Cells were then treated every three days with either

DMSO + ART (dark blue), $10 \mu \mathrm{M} \mathrm{SP}+\mathrm{ART}$ (red), ART with no DMSO (light blue) and

1319

1320

1321

1322

1323

1324

1325

1326

1327

1328

1329

1330

1331

1332

1333

1334

1335

1336

ART with no SP (orange). The amount of HIV capsid released into the supernatant was monitored over time by p24 ELISA.

(C) Cells were collected every three days from when DMSO or SP treatments were stopped (light blue and orange lines) for protein expression analysis by Western blotting. A representative blot of the indicated proteins is shown.

The limit of detection (I.o.d.) is shown by the dotted line at $3.0 \mathrm{pg} / \mathrm{ml}$. Error bars represent the SD from three independent experiments.

Figure 6. Treatment of OM-10.1 cells leads to a reduction RNA polymerase II occupancy along the HIV genome.

OM-10.1 cells on day 70 from long-term treatments with ART and $10 \mu \mathrm{M} \mathrm{SP}$ or DMSO (Fig. 4A) were set aside and stimulated for $8 \mathrm{~h}$ with $1 \mu \mathrm{M}$ prostratin. Cells were then cross-linked prepared for Chromatin immunoprecipitation (ChIP).

(A) ChIP to total RNAPII was followed by qPCR with primers specific to the indicated regions on the HIV genome (Table S2). The dark blue and red lines represent the distribution of RNAPII on the HIV genome in unstimulated cells. The light blue and orange lines represent the distribution of RNAPII on the HIV genome when cells were 
stimulated with $1 \mu \mathrm{M}$ prostratin for $8 \mathrm{~h}$ prior to crosslinking. Data for each point is plotted as a fold enrichment relative to the $\%$ of input for the unstimulated DMSO control with the first primer set. Grey asterisks mark significance comparing unstimulated SP treated to unstimulated DMSO treated cells. Black asterisks mark significance comparing stimulated SP treated to stimulated DMSO treated.

(B) As above but using an antibody specific to RNAPII CTD phosphorylated on Ser5.

(C) As above but using an antibody specific to RNAPII CTD phosphorylated on Ser2.

(D) ChIP to total RNAPII was followed by qPCR with primers specific to the GAPDH promoter region or RPL13A ORF. Data for each point is plotted as a fold enrichment relative to the \% of input for the unstimulated DMSO control with the first primer set.

(E) As above but using an antibody specific to RNAPII CTD phosphorylated on Ser5.

(F) As above but using an antibody specific to RNAPII CTD phosphorylated on Ser2. ${ }^{\star} \mathrm{P}<0.05,{ }^{* \star} \mathrm{P}<0.005,{ }^{\star * \star} \mathrm{P}<0.0005$. NS unless indicated. A two-tailed T-test was performed for the comparison of the different treatment groups in $(A)-(C)$. One-way ANOVA followed by the Dunnett multiple comparisons test was used for (D)-(E). Error bars represent SD from three independent experiments.

Figure 7: Effects of SP treatment on transcriptional machinery and cell cycle progression.

(A) OM-10.1 cells treated for 108,114 and 123 days with ART and $10 \mu \mathrm{M} \mathrm{SP}$ (red bars) or DMSO (blue bar) (Fig. 1D) were collected for analysis of mRNA expression of the indicated components of TFIIH. cDNA was prepared from cell-associated RNA and qPCR performed. The results were normalized per RPL13A and plotted relative to the 
DMSO treated control (set to 100\%, dotted line). Error bars represent the SD from three independent timepoints.

(B) Left panel: A representative of three independent Western blots of the indicated proteins from OM-10.1 cells treated 108, 114 and 123 days with ART and DMSO, 10 $\mu \mathrm{M}$ SP or $10 \mu \mathrm{M}$ EPL. Right panel: Quantification of the Western blots on the left, protein expression of the indicated genes were normalized to the housekeeping gene, GAPDH or $\beta$-tubulin, and expressed relative to the corresponding DMSO treated control (set to $100 \%$, dotted line).

(C) Left panel: A representative Western blot of the indicated genes in $\mathrm{ACH}-2$ cells treated for 15 days with ART and $10 \mu \mathrm{M}$ SP or DMSO only. Right panel: Western blot quantification of three independent experiments. The protein expression levels were determined by quantification of the blots, normalized to the housekeeping gene $\beta$ tubulin, and expressed relative to the DMSO treated control (set to $100 \%$, dotted line). (D) Left panel: A representative Western blot of three independent experiments measuring the protein expression of the indicated genes over time (d0, d3, d6 and d21). OM-10.1 cells were treated with ART $+10 \mu \mathrm{M} \mathrm{SP}$ or DMSO for the indicated number of days before harvesting cells for Western blot. Right panel: Quantification of the Western blots on the left for the indicated proteins, levels were normalized to the housekeeping gene, GAPDH or $\beta$-tubulin, and expressed relative to the corresponding DMSO treated control (set to 100\%).

(E) OM-10.1 cells were treated with ART + DMSO or $10 \mu \mathrm{M}$ SP for 24 days after which cells were collected for Western blot analysis of the indicated proteins. Left panel: A representative Western blot of 3 independent experiments. Right panel: Quantification 
of the three Western blots, protein expression of the indicated genes were normalized to 1384 the housekeeping gene, GAPDH or $\beta$-tubulin, and expressed relative to the 1385 corresponding DMSO treated control (set to $100 \%$ ).

(F) OM-10.1 cells were treated with ART and either DMSO, $10 \mu \mathrm{M}$ SP or $10 \mu \mathrm{M}$ EPL for $\sim 80$ days. Cell cycle stage analysis was performed by propidium iodide staining and flow cytometry $72 \mathrm{~h}$ post treatment. Left panel: A representative plot showing the degree of PI staining under each treatment condition. Right panel: A summary of the $\%$ of cells in the indicated stage of the cell cycle.

1391 Error bars represent the SD from three independent experiments. ${ }^{*} \mathrm{P}<0.05,{ }^{*} \mathrm{P}<0.01$, 1392 Dunnett multiple comparisons test.

Figure 8. Potent inhibition of HIV mRNA expression with limited effects on cellular transcription.

OM-10.1 cells were treated with ART+DMSO or ART+10 $\mu \mathrm{M} \mathrm{SP}$ for 15 days (until HIV capsid production in supernatant in SP-treated cells stabilized below the limit of detection by p24 ELISA) followed by an $8 \mathrm{~h}$ stimulation (or not) with $1 \mu \mathrm{M}$ prostratin. mRNA-seq and differential expression analysis was performed on these cells. Data are 1401 from two biological replicates.

1402 (A) Volcano plots showing differentially expressed genes under the indicated conditions. 1403 HIV encoding genes are colored red and the most significantly differentially expressed 1404 genes are colored blue $[\mathrm{pAdj}<1 \mathrm{e}-10$ \& abs(log2FoldChange $)>1$ for SP vs DMSO 1405 comparisons (left and right panels), and padj<1e-30 with an abs(log2FoldChange) $>2.5$ 
1406 for Stim vs No stim comparisons (middle two panels)]. The horizontal dotted line 1407 represents a pAdj $=0.05$ and the vertical dotted lines a log2FC of 1 and -1 . Left panel: 1408 The change in expression of all genes (dots) in SP treated compared to DMSO treated 1409 cells without stimulation. Middle left panel: Differentially expressed genes in DMSO 1410 treated cells stimulated with prostratin compared to unstimulated cells. Middle right 1411 panel: Differentially expressed genes in SP treated cells stimulated with prostratin 1412 compared to unstimulated cells. Right panel: Differentially expressed genes in prostratin 1413 stimulated cells treated with SP compared to DMSO.

1414 (B) GSEA Bubble-Lattice Plot of selected gene sets. The color represents the 1415 normalized enrichment score (NES) indicating the number and differential intensity of 1416 the assessed genes in each indicated pathway. NES > 0: the gene set is enriched in the 1417 SP treated sample (red). NES < 0: the gene set is enriched in the DMSO treated sample 1418 (blue). NS = unstimulated, Stim = prostratin stimulated. The size of the dots indicates 1419 the statistical significance of the enrichment found (log transformed familywise error 1420 rate, $-\log 10$ FWER $p$ value). GSEAs were computed from the GSEA app v4.1.0 using 1421 TPMs as counts and publicly available gene sets current as of October 2020 (71).

1422 (D) Heat map of expression levels (transcript per kilobase million (TPM) values) for 1423 selected genes with DMSO or SP treatment, with and without stimulation with prostratin. 


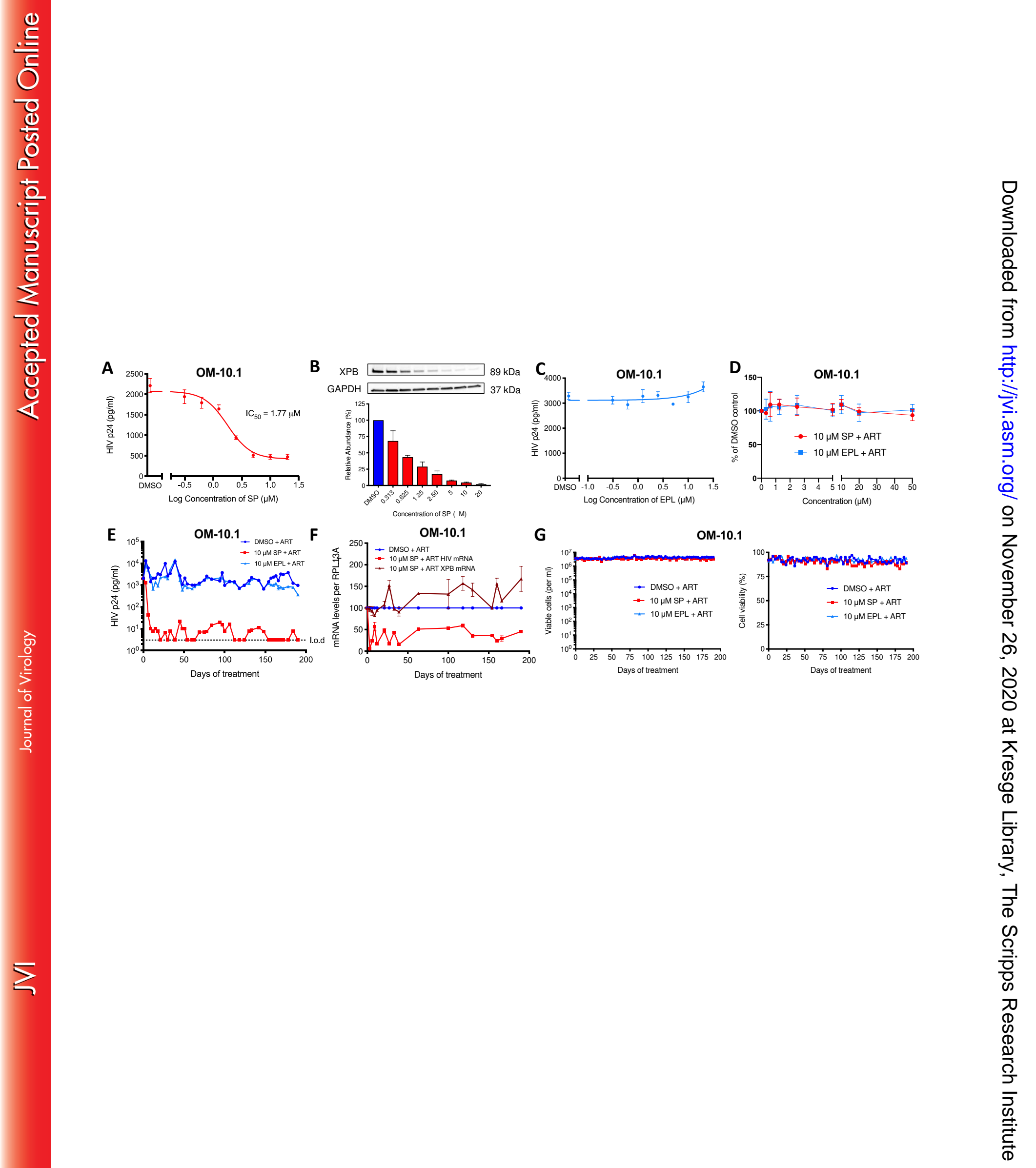




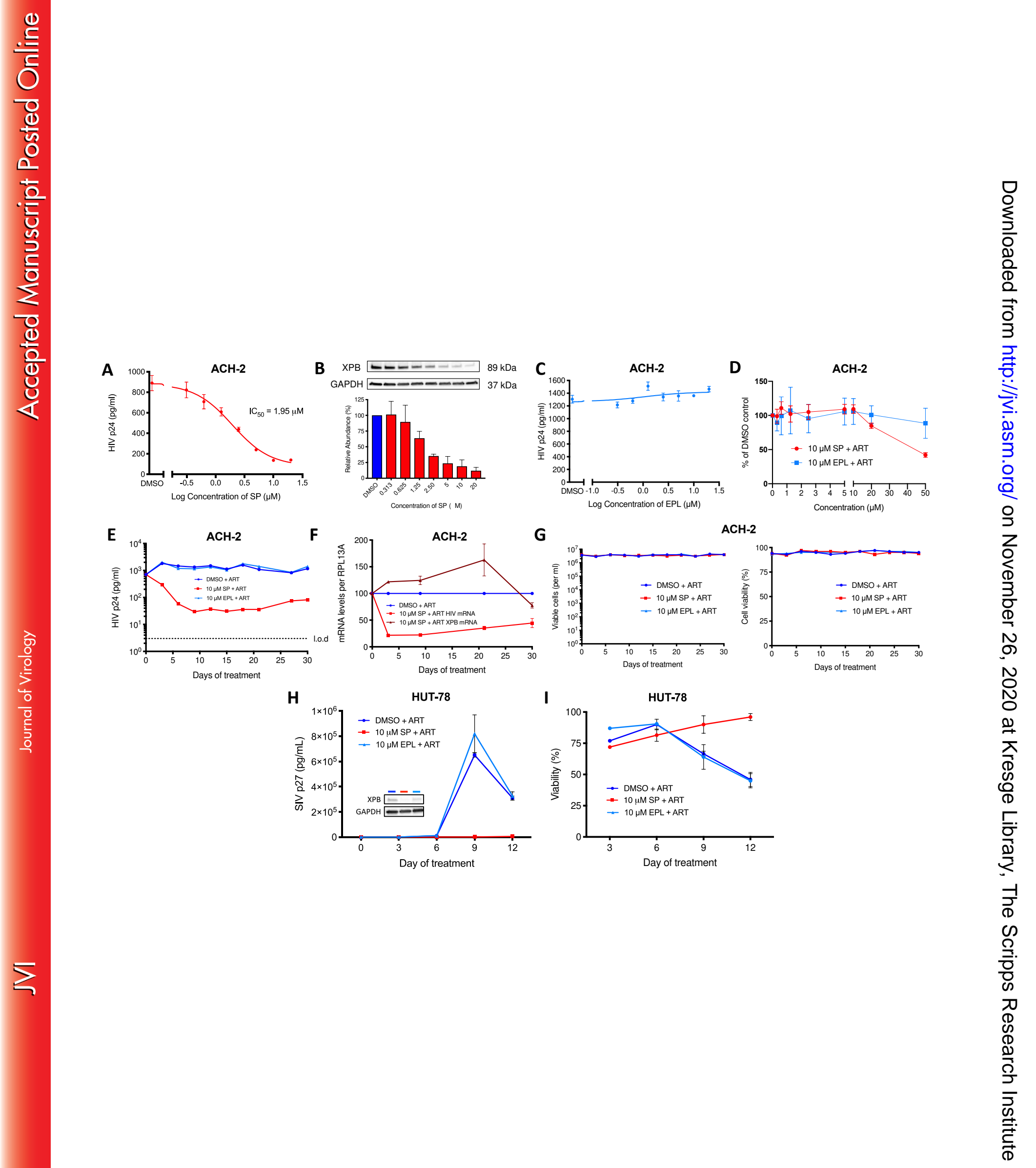




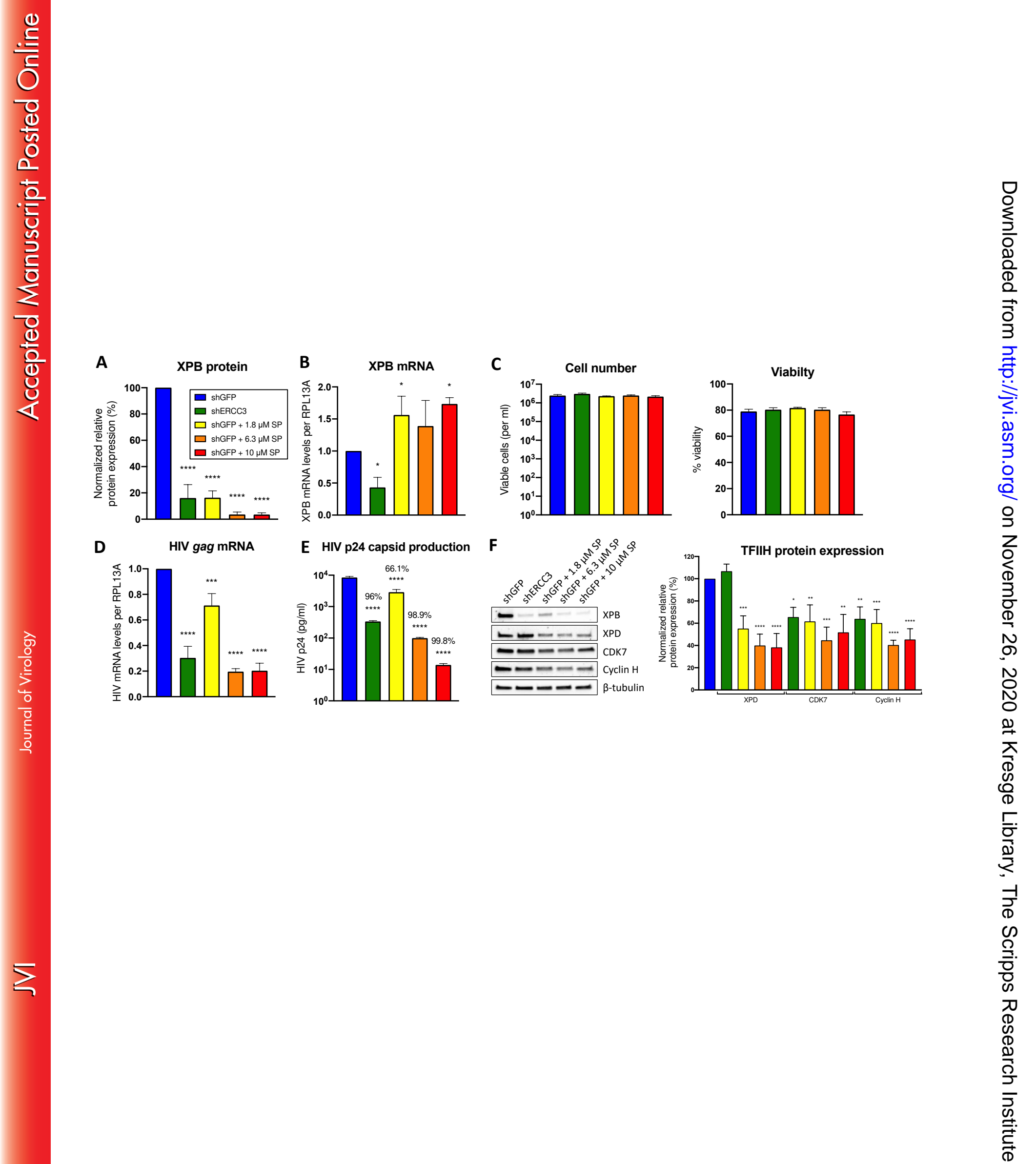


